\title{
Spheroid transplantable and functional retinal pigment epithelium derived from non-colony dissociated human induced pluripotent stem cells
}

\section{Xiaoling Guo}

Key laboratory for Rgenerative Medicine, Ministry of Education,Jinan University,Guangzhou ,China

Deliang Zhu

Key Laboratory for Regenerative Medicine, Ministry of Education,Jinan University, Guangzhou,China

Ruiling Lian

Eye Institute,Medical College of Jinan University,Guangzhou ,China

Qiaolang Zeng

Eye Institute,Medical College of Jinan University,Guangzhou,China

\section{Sanjana Mathew}

Key Laboratory for Regenerative Medicine,Ministry of Education,Jinan University ,Guangzhou,China

\section{Shibo Tang}

Aier School of Opthalmology,Central South University,Changsha,China

Jiansu Chen ( $\nabla$ chenjiansu2000@163.com )

Eye Institute, Medical College of Jinan University,Guangzhou, China

\section{Research article}

Keywords: human induced pluripotent stem cells (hiPSCs), retinal pigment epithelium (RPE), differentiation, spheroid, transplantation

Posted Date: May 22nd, 2020

DOI: https://doi.org/10.21203/rs.2.21874/v2

License: (c) (1) This work is licensed under a Creative Commons Attribution 4.0 International License. Read Full License 


\section{Abstract}

Background: Retinal pigment epithelium (RPE) cells derived from human induced pluripotent stem cells (hiPSCs) exhibit great promise in treating retinal degenerative diseases. Here, we would explore the feasibility of non-colony dissociated hiPSCs to differentiate into functional RPE cells (hiPSC-RPE), and offer an alternative transplantation method based on cell spheroids.

Methods: hiPSC-RPE cells were identified using reverse transcription-polymerase chain reaction (RT-PCR), immunofluorescence assay, Western blotting, and flow cytometry assay. The functions of hiPSC-RPE cells in vitro and in vivo were assessed by fluorescein leakage test, transepithelial electrical resistance (TEER) assay, atomic force microscopy observation, POS phagocytosis assay, frozen tissue sections, live/dead assay, SA- $\beta$-Gal staining, and immunocytochemistry.

Results: hiPSC-RPE cells positively expressed biomarkers of RPE cells but not iPSCs, such as CRALBP (97.4\%), EMMPRIN (93.8\%), Oct4 (2.1\%), and Sox2 (2.0\%). hiPSC-RPE cells displayed RPE-like characteristics including barrier function, phagocytic activity, and polarized membrane. The cells derived from hiPSC-RPE spheroids positively expressed Nestin and exhibited reduced SA- $\beta$-Gal staining. hiPSCRPE cell spheroids could form monolayer on decellularized corneal matrixes (DCM). After one month of subretinal transplantation, hiPSC-RPE cell spheroids could survive and maintain segmental sheet growth in sodium iodate $\left(\mathrm{NaIO}_{3}\right)$ induced RPE-degenerated chinchilla rabbits.

Conclusion: This study suggested that non-colony dissociated hiPSCs were effectively differentiated into functional RPE cells, and hiPSC-RPE cell spheroids maintained segmental sheet growth in the subretinal of RPE degenerate chinchilla rabbits in vivo, which may lay the foundation for cell spheroid transplantation as an alternative method for RPE degenerative disease therapy in the future.

\section{Background}

Retinal pigment epithelium (RPE) cells are polarized monolayer cells distributed between the choriocapillaris and neural retina, playing the crucial role in maintaining the function of photoreceptors and the retina [1]. Degeneration and dysfunction of RPE cells resulting in photoreceptor loss are the main causes of retinal diseases including Stargardt's macular dystrophy and dry age-related macular degeneration (AMD) [2]. Since there is no cure for most patients affected by these diseases, RPE cell transplantation represents an attractive therapeutic alternative [3]. Various cell types have been examined for their utility in RPE cell replacement including ARPE19 cells [4], adult RPE cells [5], fetal RPE cells [6], and other non-RPE cell lines [7-9]. However, sources of donor cells are still very limited and sometimes can cause immunological rejection.

Human pluripotent stem cells (hPSCs) including human embryonic stem cells (hESCs) and human induced pluripotent stem cells (hiPSCs) are characterized of unlimited self-renewal and their ability to differentiate into any cell type. In 2004, Klimanskaya et al. firstly reported that putative RPE cells could be derived from spontaneous differentiation of ESCs [10]. However, the application of ESCs has ethical and 
immune rejection problems. iPSCs without ethical issue can be derived from the patient's own cells, and HLA-matched or CRISPR-engineered iPSCs can also been made based on the current gene editing technology, avoiding the problem of immune rejection. So far, a number of researchers have reported that iPSCs can be differentiated into RPE-like cells (iPS-RPE) [3, 11-13], but these iPSCs were based on traditional colony culture for differentiation.

Recently, scientists developed a non-colony but monolayer culture method for dissociated cells [14, 15]. The key element in this technology is seeding dissociated cells at high density on Matrigel coating plates in the presence of ROCK inhibitor (Y27632) to facilitate dissociated-cell plating efficiency. One of the advantages of non-colony dissociated culture is the generation of homogeneous hiPSCs. Chen et al. found that cells under non-colony dissociated culture showed a more homogeneous response to BMP-4 signaling than WA01 cells in colony [14]. Our previous study also demonstrated that a half-exchange mTeSR1 medium (HM) culture system that combined Y27632 and high-density dissociated-cell seeding could facilitate the homogeneous growth of hiPSCs [16]. So we would use this method of non-colony dissociated culture to harvest homogeneous hiPSCs for RPE differentiation in this study.

So far, two approaches for RPE cell transplantation in vivo are predominate: the subretinal injection of cell suspension or the subretinal insertion of RPE cell sheet grown in monolayer $[17,18]$. Subretinal transplantation of pluripotent stem cell (PSC)-derived RPE cell suspensions or RPE-containing scaffold sheets have been found to be safe and have rescued vision in animal models and even in patients with retinal degeneration [19-23]. Polarized cell monolayer transplantation could improve cell survival compared with cell suspension transplantation, but the process of cell sheet transplantation is not easy [17]. So exploration more alternative methods for RPE cell transplantation in vivo is necessary.

Huang YC et al. reported that use of the appropriate size of dermal papilla (DP) spheroids could effectively induce hair follicle regeneration and maintain high cell viability when transplanted in vivo [24]. Our previous studies plus other work also confirmed that spheroid culture could enhance cellular stemness and viability in bovine corneal endothelial cells (B-CECs), corneal stromal cells (CSCs), and human adipose-derived stem cells (ADSCs) [25-27]. These research foundations inspired us to generate spheroids of RPE cells derived from human iPSCs (hiPSC-RPE) for transplantation in vivo. In this study, hiPSC-RPE cell spheroids were generated based on commercially available silicone micro-wells, which can be used to upscale the production of cell spheroids with a controllable size.

Schwartz et al. provided the first description of hESC-RPE transplanted into two human patients with macular degeneration, which showed that hESC-RPE had no signs of hyperproliferation, tumorigenicity, ectopic tissue formation, or apparent rejection after 4 months[2]. Then, Schwartz et al. further reported hESC-RPE cells were transplanted into nine patients with Stargardt's macular dystrophy (age $>18$ years) and nine AMD patients (age $>55$ years) for a median of 22 months, and suggested that hESC-RPE cell transplantation could improve patients' vision and had no evidence of adverse proliferation, rejection, or serious ocular or systemic safety issues [28]. Significantly, in 2017, Takahashi et al. firstly performed iPSRPE-based autologous cell transplantation for treatment of neovascular AMD in one patient, and no 
serious adverse events were noted after one year of follow-up [29]. In addition, Westenskow et al. reported that the iPS-RPE grafts remained viable and did not induce any obvious pathological changes in rats [30]. One month of transplantation of hESC-derived retinal progenitors (RPs) into the sub-retinal space of sodium iodate $\left(\mathrm{NaIO}_{3}\right)$ induced RPE degeneration adult rabbits, transplanted retinal cells survived, migrated into retinal layers, and restored a small but significant b-wave of ERG testing [31]. Moriguchi et al. explored the mechanism causing degeneration of RPE in mice after an intravenous injection of $\mathrm{NaIO}_{3}$ [32]. So, in our study, we would also use $\mathrm{NaIO}_{3}$ treatment to establish RPE degeneration model in chinchilla rabbits for cell transplantation in vivo.

In this study, we would examine the feasibility of non-colony dissociated hiPSCs instead of clonal hiPSCs to differentiate into transplantable and functional RPE cells. Then, we seeded hiPSC-RPE cell spheroids onto decellularized corneal matrixes (DCM) for simulation experiments in vitro. Lastly, we injected hiPSCRPE cell spheroids into the subretinal space of chinchilla rabbits with RPE degeneration induced by $\mathrm{NaIO}_{3}$ treatment in vivo. Our study will lay the foundation for the use of hiPSC-RPE cell spheroids as an alternative method for cell transplantation to therapy of RPE degenerative diseases.

\section{Material And Methods}

\section{Culture of hiPSCs}

hiPSCs were a gift from the Guangzhou Institutes of Biomedicine and Health, Chinese Academy of Sciences. These hiPSCs were reprogrammed from human umbilical cord mesenchymal cells using methods described in a previous report [33]. hiPSCs were cultured in 1\% Matrigel (BD Biosciences, USA) coated dishes at $37^{\circ} \mathrm{C}, 5 \% \mathrm{CO}_{2}$ and refreshed daily with mTeSR1 medium (StemCell Technologies Inc., Canada). They were passaged once every 6 days with $0.25 \%$ EDTA (Sigma, USA) and were then seeded into 6-well dishes at a ratio of 1:6. They were supplemented with $10 \mu \mathrm{M} \mathrm{Y-27632} \mathrm{(Sigma)} \mathrm{on} \mathrm{the} \mathrm{first} \mathrm{day}$ of passaging. For generating dissociated hiPSCs, the harvested clonal hiPSCs were pipetted approximately 30-50 times and then were filtered through a $40 \mu \mathrm{m}$ cell strainer (BD). The dissociated hiPSCs $\left(1 \times 10^{5}\right.$ cells $\left./ \mathrm{cm}^{2}\right)$ were plated into 6 -well dishes. Half-exchange mTeSR1 medium (HM) was used for further culture of non-colony dissociated hiPSCs [16].

\section{Isolation and culture of adult RPE cells}

Human eyes were obtained from six male donors without ocular disease after informed consent at the mean age of $45 \pm 5$ years old. The study was approved by the Human Research and Ethical Committee of Jinan University, and the procurement and use of human tissues were in compliance with the Declaration of Helsinki. Human adult RPE cells were isolated and cultured as described in a previous report [34]. Briefly, RPE cells were isolated from the posterior section of the eyeballs using $0.25 \%$ EDTA-trypsin (Gibco, USA) and harvested by centrifugation at $400 \times \mathrm{g}$ for $5 \mathrm{~min}$. hRPE cells were cultured in RPE medium that consisted of high-glucose Dulbecco's modified Eagle's medium (HG-DMEM, Gibco), 10\% FBS (Gibco), 100 $\mathrm{U} / \mathrm{mL}$ penicillin and $100 \mathrm{mg} / \mathrm{mL}$ streptomycin (P/S, Gibco) at $37^{\circ} \mathrm{C}$ and $5 \% \mathrm{CO}_{2}$. After reaching $100 \%$ 
confluence, RPE cells were passaged and seeded in 6-well plates with a 1\% Matrigel coating (Sigma). The medium containing $100 \mathrm{ng} / \mathrm{mL}$ Activin A (R\&D Systems, USA) was changed every 3 days.

\section{Differentiation of non-colony dissociated hiPSCsinto RPE cells}

The point at which dissociated hiPSCs expanded to $100 \%$ confluence in HM was defined as day -2 , and from day -2 to 0 , hiPSCs were cultured in E7 medium without FGF2 but with $10 \mu \mathrm{M} \mathrm{Y-27632.} \mathrm{Prior} \mathrm{to} \mathrm{the}$ beginning of differentiation, dissociated hiPSCs were cultured in proneural medium containing DMEM/F12 (Gibco), 1\% nonessential amino acids (NEAA, Invitrogen, USA), and 1\% N2 (Invitrogen). From 0-2 days, $10 \mathrm{ng} / \mathrm{mL}$ IGF-1 (R\&D Systems), $50 \mathrm{ng} / \mathrm{mL}$ Noggin (R\&D Systems), $10 \mathrm{ng} / \mathrm{mL}$ Dkk-1 (R\&D Systems), and $10 \mathrm{mM}$ nicotinamide (NIC, Sigma) were added into the proneural medium. From 2-4 days, $10 \mathrm{ng} / \mathrm{mL}$ IGF-1, $10 \mathrm{ng} / \mathrm{mL}$ Noggin, $10 \mathrm{ng} / \mathrm{mL}$ Dkk-1, $10 \mathrm{mM} \mathrm{NIC}$, and $5 \mathrm{ng} / \mathrm{mL} \mathrm{bFGF}$ were added to the proneural medium. From 4-6 days, $10 \mathrm{ng} / \mathrm{mL}$ IGF-1, $10 \mathrm{ng} / \mathrm{mL}$ Dkk-1, and $100 \mathrm{ng} / \mathrm{mL}$ Activin A were added to the proneural medium. From 6-14 days, $100 \mathrm{ng} / \mathrm{mL}$ Activin A and $10 \mu \mathrm{M}$ SU5402 (EMD Millipore, Germany) were added to the proneural medium. Then, the differentiated cells were mechanically enriched by scraping away cells with non RPE-like (spindle) morphology, and the remaining RPE-like (epithelioidlike) cells were passaged using $0.25 \%$ EDTA and seeded into $1 \%$ Matrigel coating dishes. From 14-20 days, the enriched cells were cultured in enrichment medium containing HG-DMEM (Gibco), 1\% FBS (Gibco), $100 \mathrm{ng} / \mathrm{mL}$ Activin A, 1×sodium pyruvate, and 1×GlutaMAX (Invitrogen). From 20-30 days, these enriched cells were passaged again as passage 1 (P1) and cultured in RPE medium.

\section{Gene expression analysis}

Total RNAs from the cells was isolated using a Tissue RNA Miniprep Kit (Biomega, China). These RNAs were reversely transcribed into cDNA using the Superscript II kit (Invitrogen), and cDNAs were synthesized and used for reverse transcription-polymerase chain reaction (RT-PCR) to identify gene expressions such as GADPH, Nanog, Oct4, Sox2, Klf4, RPE-65, CRALBP, EMMPRIN, Otx2, c-Myc, Lin28, Nestin, and Pax6. RTPCR products were examined after electrophoresis on $2 \%$ agarose gels. Gels were scanned for further analysis. For quantification of gene transcripts, cDNAs were first denatured at $95^{\circ} \mathrm{C}$ for $3 \mathrm{~min}$, followed by 40 cycles of $95^{\circ} \mathrm{C}$ for $10 \mathrm{~s}$ and $58^{\circ} \mathrm{C}$ for $30 \mathrm{~s}$. The relative expressions of the genes such as Nanog, Oct4, Sox2, KIf4, c-Myc, Lin28, Nestin, and Pax6 were normalized against GAPDH, and quantification was performed using the comparative $\mathrm{Ct}\left(2^{-\mathrm{DDCt}}\right)$ method. The primer sequences are shown in Table 1.

\section{Flow cytometry}

Samples including hiPSC, hiPSC-RPE, and hRPE cells were fixed using $4 \%$ paraformaldehyde and permeabilized by $0.1 \%$ Triton X-100 (Sigma). Then, they were incubated with isotype control or primary antibodies as shown in Table 2 at $4{ }^{\circ} \mathrm{C}$ for $30 \mathrm{~min}$. Primary and isotype control antibodies such as Oct4, Sox2, RPE-65, CRALBP, Mitf, and EMMPRIN were labeled with fluorophore-conjugated secondary antibodies at $4{ }^{\circ} \mathrm{C}$ for $30 \mathrm{~min}$. The labeled samples were detected by a flow cytometry analyzer (BD, USA).

\section{Immunofluorescence assay}


Immunofluorescence assay was performed to identify hiPSC-RPE cells as described in a previous report [35]. Briefly, 4\% paraformaldehyde fixed cells were permeabilized with $0.1 \%$ Triton X-100 and incubated with $3 \%(w / v)$ BSA for blocking. Cells were then incubated with primary antibodies such as CRALBP, Mitf, Tyrosinase, Otx2, EMMPRIN, RPE-65, ZO-1, Occludin, Nanog, AHNA, Nanog, Oct4, Sox2, SSEA4, TRA-1-60 as shown in Table 2 overnight at $4{ }^{\circ} \mathrm{C}$. On the second day, the cells were washed twice with PBS and then incubated with FITC-conjugated anti-mouse, FITC-conjugated anti-rabbit, Cy3-conjugated anti-mouse, or Cy3-conjugated anti-rabbit IgG secondary antibodies (1:1000, concentration of $1 \mathrm{mg} / \mathrm{mL}$, Bioword, USA) at room temperature for $60 \mathrm{~min}$. Cells were rinsed 3 times with PBS and stained with DAPI (Sigma) before examination by a fluorescence microscope (OLYMPUS, Japan).

\section{Fluorescein leakage test}

A fluorescein leakage test (FLT) was used to assess the barrier function of the epithelial cells as described in a previous report [36]. First, $200 \mu \mathrm{L}$ of cells $\left(1 \times 10^{5} \mathrm{cells} / \mathrm{cm}^{2}\right)$ were seeded in 6 -transwell inserts (Millipore, USA) and incubated at $37{ }^{\circ} \mathrm{C}$ and $5 \% \mathrm{CO}_{2}$. After reaching $100 \%$ confluence, cells were fixed with $4 \%$ paraformaldehyde, and $500 \mu \mathrm{L}$ of Na-fluorescein solution $(10 \mu \mathrm{g} / \mathrm{mL}$, Sigma) was added into each insert before incubation for the designated times $(0,4,12,24$, and $36 \mathrm{~h}$ ) to allow solution leakage into the bottom wells. The values of fluorescein leakage into the wells were measured using a microplate spectrophotometer (VSERSA Max, USA) at $485 \mathrm{~nm}$ excitation and $530 \mathrm{~nm}$ emission wavelengths. The fluorescein leakage through the inserts without cells was set as $100 \%$ (maximum leakage). The values of fluorescein leakage test (FLT) were calculated as the amount of fluorescein leakage from hRPE and hiPSC-RPE cells compared to the corresponding maximum leakage.

\section{Transepithelial electrical resistance (TEER) assay}

A TEER assay was used to assess the dynamic barrier function of the epithelioid cells [37]. Cells were seeded into 24 -transwell inserts at $1 \times 10^{5}$ cells $/ \mathrm{cm}^{2}$. After reaching $100 \%$ confluence on day 7 , the dynamic barrier of the cells was determined through measuring TEER across the cell monolayer using Millicell-ERS-2 (Millipore, Temecula, USA). The value of TEER was calculated per the following equation:

$\operatorname{TEER}\left(\Omega \mathrm{cm}^{2}\right)=\left(\mathrm{R}_{\text {total }}-\mathrm{R}_{\text {insert w/o Matrigel }}\right) \times \mathrm{A}$

$R_{\text {total }}$ is the resistance measured $(\Omega), R_{\text {insert w/o Matrigel }}(\Omega)$ is the resistance of the insert without $1 \%$ Matrigel coating, and $A$ is the membrane area $\left(\mathrm{cm}^{2}\right)$ of the insert.

\section{Atomic force microscopy observation}

Atomic force microscopy (AFM) was used to observe the ultrastructure of cells as described in a previous report [38]. Cells were fixed with $4 \%$ paraformaldehyde for $10 \mathrm{~min}$ and dried at room temperature before imaging. The curvature radius of the AFM tips was $10 \mathrm{~nm}$. The spring constant was 20-50 N/m with a resonance frequency of $278-317 \mathrm{kHZ}$. The scanning speed was kept at $0.5 \mathrm{~Hz}$. The ultrastructure of the 
cells was measured in contact mode. The data analysis was performed using Nanoscope Analysis Software (Thermo Microscopes Proscan Image Processing Software Version 2.1, USA).

\section{POS phagocytosis assay}

The photoreceptor outer segment (POS) was isolated as described in a previous report [39]. Briefly, the retinas of porcine eyeballs were collected and agitated in $\mathrm{KCl}$ buffer $\left(0.5 \mathrm{mM} \mathrm{CaCl}_{2}, 1 \mathrm{mM} \mathrm{MgCl}, 0.3 \mathrm{M}\right.$ $\mathrm{KCl}$, and $10 \mathrm{mM} \mathrm{HEPES}$ ) with $48 \% \mathrm{w} / \mathrm{v}$ sucrose at $\mathrm{pH} 7.0$, and then were centrifuged at $5000 \times \mathrm{g}$ for $5 \mathrm{~min}$. The supernatant containing the POS was filtered using sterile gauze, diluted 1:1 with $\mathrm{KCl}$ buffer without sucrose, and centrifuged at $4000 \times \mathrm{g}$ for $10 \mathrm{~min}$. The isolated POS were then resuspended in $1 \mathrm{~mL}$ of PBS and were labeled with FITC (Sigma-Aldrich) at room temperature for $1 \mathrm{~h}$. The labeled FITC-POS were then rinsed and resuspended using HG-DMEM medium with $5 \%$ sucrose. Cells were incubated with FITC-POS at $37{ }^{\circ} \mathrm{C}$ and $5 \% \mathrm{CO}_{2}$ for $2 \mathrm{~h}$. Last, immunofluorescence was performed using Cy3-conjugated mouse monoclonal antibody ZO-1 and DAPI, and then they were examined under an inverted fluorescence microscope (OLYMPUS, Japan).

\section{Z-stack confocal microscopy polarized membrane observation}

Z-stack confocal microscopy was used to observe the polarized membrane of the cells. First, $200 \mu \mathrm{L}$ of cells $\left(1 \times 10^{5}\right.$ cells $\left./ \mathrm{cm}^{2}\right)$ were seeded into 6 -well dishes and incubated at $37^{\circ} \mathrm{C}$ and $5 \% \mathrm{CO}_{2}$ for 5 days. Immunofluorescence was conducted with Cy3-conjugated mouse monoclonal antibody ZO-1 and DAPI and the stained cells were examined under a confocal microscope (LSM 510 META; Zeiss, Thornwood, USA).

\section{Western blotting}

Cells were washed using cold PBS and lysed using RIPA (Beyotime Biotechnology, China). A total of 50 $\mu \mathrm{g}$ of protein was electrophoresed on 10\% SDS-PAGE gels and then transferred to polyvinylidene fluoride membranes (PVDF, Sigma) and blocked using $5 \%$ fat-free milk. Then, the membranes were incubated with primary antibodies such as RPE-65, CRALBP, EMMPRIN, Mitf, Otx2, Tyrsosinase, Nanog, Oct4, Sox2, $\mathrm{KIf} 4$, Nestin, GADPH, and b-Actin as shown in Table 2 at $4{ }^{\circ} \mathrm{C}$ overnight. The membranes were washed 5 times with TBST and incubated with HRP-conjugated anti-mouse or anti-rabbit IgG secondary antibodies (1:3000, concentration of $1 \mathrm{mg} / \mathrm{mL}$, Bioword) at room temperature for $2 \mathrm{~h}$. Bands were visualized with enhanced chemiluminescence (ECL, Pierce, USA).

\section{Production of agarose micro multiwell dishes and hiPSC-RPE cell spheroids}

A volume of $500 \mu \mathrm{L}$ liquid solution of $2 \%(\mathrm{~g} / \mathrm{mL})$ agarose was pipetted into an commercially available silicone micro-mold with eighty-one wells (Micro Tissues Inc., CA, USA). After solidification, the microwell agarose mold was removed using sterilized forceps. The agarose molds were placed in 6-well dishes. Then, $200 \mu \mathrm{L}$ of cell suspension containing approximately $2 \times 10^{5}$ cells was carefully pipetted into the 
microwell plate and incubated at $37^{\circ} \mathrm{C}$ and $5 \% \mathrm{CO}_{2}$. The medium was changed every 2 days. Cell spheroids (approximately $80 \mu \mathrm{m}$ diameter, $5 \times 10^{3}$ cells/spheroid) were formed after 3 days.

\section{Preparation of decellularized corneal matrix (DCM)}

The lamellar corneal matrix (100 $\mu \mathrm{m}$ thickness) was excised from porcine eyeballs using a microkeratome (Kangming, China) and was rinsed 3 times with PBS. The excised lamellar corneal matrix was treated with $0.25 \%$ EDTA-trypsin (Invitrogen) at $37^{\circ} \mathrm{C}$ for $30 \mathrm{~min}$, and then was fixed with $4 \%$ paraformaldehyde for 1 day at $4{ }^{\circ} \mathrm{C}$. It was then treated with $0.8 \%$ SDS (Sigma) solution at $-80^{\circ} \mathrm{C}$ for 30 min and then was transferred to a $37^{\circ} \mathrm{C}$ shaking table $(350 \mathrm{rpm})$ for $1 \mathrm{~h}$. It was then rinsed 3 times with PBS and preserved in $100 \%$ glycerol at $4{ }^{\circ} \mathrm{C}$ as decellularized corneal matrix (DCM). Before the seeding of cells, the DCM was washed 3 times with PBS containing P/S solution and sterilized under ultraviolet light for $2 \mathrm{~h}$.

\section{Seeding the cell spheroids on the DCM}

To test whether cell spheroids in the biomimetic microenvironment could grow well, an in vitro simulation experiment of seeding cell spheroids onto DCM was conducted as described previously [26]. Briefly, cell spheroids were seeded on the DCM. The medium containing $10 \mu \mathrm{M} \mathrm{Y-27632} \mathrm{was} \mathrm{changed} \mathrm{every} 3$ days. Viable cell staining with Calcein AM was used for better observation of the cell spheroids on the DCM under a fluorescent microscope. The adherent growing area of the cell spheroid periphery stained by a Live-Dead Cell Staining Kit (Biotium, USA) was measured using Image J on days 7 and 14, respectively.

\section{Frozen tissue sections}

Tissue samples firstly were fixed with $4 \%$ paraformaldehyde for $15 \mathrm{~min}$, and then were mounted using tissue freezing medium (SAKURA Tissue-Tek, USA) and placed at $-80^{\circ} \mathrm{C}$ refrigerator for at least $2 \mathrm{~h}$ until frozen. The frozen tissues were sectioned at a thickness of $15 \mu \mathrm{m}$ using a cryo-microtome (Thermo Fisher, USA) as described in a previous report [40]. Sections were placed on one side of microscope slides (SAKURA Tissue-Tek, USA). Some sections were incubated with DAPI for $15 \mathrm{~min}$, washed with PBS for 3 times, and examined under an inverted fluorescence microscope (OLYMPUS, Japan). Other sections were used for hematoxylin-eosin (H\&E) staining and were imaged using an inverted microscope (Nikon, Japan).

\section{Live/dead assay of Calcein AM and EthD-III double staining}

Calcein AM and EthD-III double staining (Molecular Probes, USA) was performed as described in a previous report[16]. Briefly, a standard working solution containing $2 \mu \mathrm{M}$ Calcein-AM and $4 \mu \mathrm{M}$ EthD-III was prepared. Cells were incubated with the standard working solution at room temperature for $40 \mathrm{~min}$, and were then imaged under an inverted fluorescence microscope.

\section{SA- $\beta$-Gal stainingassay}


SA- $\beta$-Gal staining was performed using a Cellular Senescence Assay Kit (Beyotime Biotechnology, China) following the manufacturer's instructions. We used spheroid or monolayer adherent cells on day 7 and 14 to conduct SA- $\beta-$ Gal staining. Briefly, after reaching $100 \%$ confluence, the cells were fixed with $4 \%$ paraformaldehyde for $15 \mathrm{~min}$ at room temperature and were then incubated in a staining solution overnight at $37^{\circ} \mathrm{C}$. On the next day, the stained cells were washed with PBS and observed under an inverted microscope. A blue color indicated the presence of SA- $\beta-G$ al. The intensity of the SA- $\beta-G$ al staining was calculated using ImageJ software.

\section{Tagging hiPSC-RPE cells with PKH26}

The standard protocol was performed as described on the PKH26 Product Information Sheet (MINI2, Sigma). Briefly, a suspension containing $2 \times 10^{7}$ cells was centrifuged $(400 \times \mathrm{g}, 5 \mathrm{~min}$ ) and washed once using fresh medium without serum. After centrifuging, the cells were resuspended in $1 \mathrm{~mL}$ of Diluent $\mathrm{C}$. Dye Solution $\left(4 \times 10^{-6} \mathrm{M}\right)$ was prepared by adding $4 \mu \mathrm{L}$ of PKH26 ethanolic dye solution into $1 \mathrm{~mL}$ of Diluent $\mathrm{C}$. Then, $1 \mathrm{~mL}$ of Dye Solution was rapidly added to the cell suspension. The final concentration after mixing was $2 \times 10^{-6} \mathrm{M} \mathrm{PKH} 26$ with $1 \times 10^{5} \mathrm{cells} / \mathrm{cm}^{2}$. The mixing suspension was incubated with periodic mixing at room temperature for $5 \mathrm{~min}$. The staining was stopped by adding an equal volume (2 $\mathrm{mL}$ ) of serum. Then, the suspension was centrifuged at $400 \times \mathrm{g}$ for 10 min and washed 3 times. Finally, cells tagged with $\mathrm{PKH} 26$ were used for injection.

\section{RPE degeneration chinchillarabbitmodel}

Rabbits were weighed on an electronic scale and then injected with $1 \% \mathrm{NalO}_{3}(40 \mathrm{mg} / \mathrm{kg}$, Sigma) via the ear marginal vein. After one week, the rabbits were injected with $1 \% \mathrm{NaIO}_{3}(40 \mathrm{mg} / \mathrm{kg})$ again. The successful lesioned models were assessed by ERG assay using the Roland Retiport (RETI-Port/Scan 21) system, which showed no distinctly functional ERG response compared with normal rabbits under similar excitation. Then, these successful models would be used for following cell transplantation.

\section{Preliminary test of hiPSC-RPE cell spheroids in vivo}

Animal experiments were approved by the Institutional Animal Care and Use Committee of Jinan University, and animal procedures were conducted following the guidelines of the US National Institutes of Health. Twelve six-month-old chinchilla rabbits with a weight of $1-2 \mathrm{~kg}$ were raised in a $12 \mathrm{~h}$ dark/light cycle, temperature at $23 \pm 2{ }^{\circ} \mathrm{C}$, and relative humidity of $45 \%$ to $55 \%$. Water and food were changed every day. These chinchilla rabbits were randomly separated into four groups: control group ( $n=3,6$ eyes), which received no treatment; $\mathrm{Na}_{2} \mathrm{IO}_{3}$ group ( $\mathrm{n}=3,6$ eyes), which received $\mathrm{Na}_{2} \mathrm{IO}_{3}$ treatment; $\mathrm{Na}_{2} \mathrm{IO}_{3}+\mathrm{PBS}$ group ( $n=6,6$ right eyes), which received $\mathrm{Na}_{2} \mathrm{IO}_{3}$ treatment and PBS injection; and the $\mathrm{Na}_{2} \mathrm{IO}_{3}+$ hiPSC-RPE group ( $n=6,6$ left eyes), which received $\mathrm{Na}_{2} \mathrm{IO}_{3}$ treatment and hiPSC-RPE cell injection. The leakage or bystander effects were excluded through the inspection of different people. Water containing $210 \mathrm{mg} / \mathrm{L}$ cyclosporin A (Sigma) and prednisone were given to these rabbits throughout the experiment to reduce allograft rejection. For PBS or hiPSC-PRE cell injection, the model rabbits were anesthetized with 
pentobarbital sodium ( $25 \mathrm{mg} / \mathrm{kg}$, Sigma) and chlorpromazine ( $5 \mathrm{mg} / \mathrm{kg}$, Sigma). The pupil was dilated using tropicamide (Alcon, Canada) and the eye lid was kept open using a lid speculum. Cell transplantation was performed under a surgical microscope (Ocular Instruments, China) [41]. For subretinal injection, the peritomy was made $2.0 \mathrm{~mm}$ posterior to the limbus in the superotemporal quadrant of each eyeball. A sideport knife Beaver blade (BD) was used to make a longitudinal triangular scleral incision starting $2 \mathrm{~mm}$ away from the limbus at about the $5^{\circ}$ axis toward the choroid until minimal blood reflux appeared. At this point an additional tract through the choroid toward the RPE layer was created using a 30-gauge needle. The hiPSC-RPE cell spheroids labeled with PKH26 were suspended in PBS containing $10 \mu \mathrm{M} Y-27632$, and then $10 \mu \mathrm{L}$ of cell spheroids (approximately $1 \times 10^{5}$ cells) at a density of 20 cell spheroids/ $\mu \mathrm{L}$ were slowly injected through the scleral tunnel using a $50 \mu \mathrm{L}$ Hamilton blunt syringe with a 30-gauge needle (BD), then the syringe was immediately pulled back.

\section{Electroretinographic (ERG) Analysis}

ERG was recorded using an Espion ERG Diagnosys machine (Diagnosys, Littleton, MA, USA) [42]. In brief, pigment rabbits were anesthetized with pentobarbital sodium ( $25 \mathrm{mg} / \mathrm{kg}$, Sigma) and chlorpromazine (5 $\mathrm{mg} / \mathrm{kg}$, Sigma) after overnight dark adaption. Eyeballs were anesthetized with oxybuprocaine (Alcon, Ontario, Canada) and pupils were dilated with compound tropicamide (Alcon, Ontario, Canada). Flash ERG waves were measured using a gold wire corneal electrode, a forehead reference electrode, and a ground electrode near the tail. Scotopic, rod-mediated responses were obtained from dark-adapted animals at the following increasing light intensities: $0.1,1$ and $10 \mathrm{~cd} . \mathrm{s} / \mathrm{m}^{2}$. Photopic, cone-mediated responses were performed following 10-minute light adaptation on the background light intensity of 30 cd. $\mathrm{s} / \mathrm{m}^{2}$. Recordings were obtained at the light intensity of $10 \mathrm{~cd} . \mathrm{s} / \mathrm{m}^{2}$. The ERG a-wave amplitudes were measured from the baseline to the negative peak and the b-wave was measured from the trough of the a-wave to the peak of the positive wave, or when the a-wave was not present, from baseline to the peak of the first positive wave.

\section{Immunocytochemistry}

Rabbits were sacrificed with an overdose of sodium pentobarbital. Their eyeballs were removed, punched using a 23-gauge needle (BD), and fixed in $4 \%$ paraformaldehyde overnight at $4{ }^{\circ} \mathrm{C}$. Then, these eyeballs were dehydrated with a graded series of ethanol and xylene and subsequently were embedded using paraffin wax [43]. The paraffin sections $(5 \mathrm{~mm})$ were cut and dewaxed in water. After antigen repair, these sections were fixed with $4 \%$ paraformaldehyde for $15 \mathrm{~min}$ and washed 3 times with PBS. They were permeabilized with $0.1 \%$ Triton X-100 for 15 min at room temperature and were blocked with $3 \%(\mathrm{w} / \mathrm{v})$ BSA (Sigma) at room temperature for $1 \mathrm{~h}$. Then, they were incubated with primary antibodies as shown in Table 2 for $2 \mathrm{~h}$ at room temperature followed by FITC-conjugated secondary antibody (1:1000, concentration of $1 \mathrm{mg} / \mathrm{mL}$, Bioword) for $1 \mathrm{~h}$ at room temperature. These sections were rinsed 3 times with PBS and incubated with DAPI $(10 \mu \mathrm{g} / \mathrm{mL})$ for $15 \mathrm{~min}$. Then, they were examined under an inverted fluorescence microscope. 


\section{Statistical analysis}

All of the data are presented as the mean \pm SEM of at least three separate experiments, and statistical significance was evaluated using one-way ANOVA followed by Tukey's multiple comparison tests. Student's unpaired $t$-test was used to compare two different groups. $P<0.05$ was considered statistically significant.

\section{Result}

\section{Comparison of non-colonydissociatedhiPSCsand clonal hiPSCs}

hiPSCs showed clonal growth, and the clones gradually became larger over time. The dissociated hiPSCs in non-colony culture could adherently grow well. The dissociated hiPSCs displayed a homogenized cellular state. Immunofluorescence assays demonstrated that both clonal hiPSCs and dissociated hiPSCs were positive for the expression of Nanog, Oct4, Sox2, SSEA4, and TRA-1-60 proteins (Fig. S1A). RT-PCR also showed that the genes of Nanog, Oct4, Sox2, c-Myc, KIf4, Lin28, and Nestin were expressed but the Pax6 gene was not expressed in dissociated hiPSCs and clonal hiPSCs (Fig. S1B). The results of qPCR showed that the mRNA expression levels of Nanog, Sox2, Oct4, c-Myc, KIf4, Lin28, and Nestin had no significant differences between dissociated hiPSCs and clonal hiPSCs (Fig. S1C). The chromosomal stabilities of the dissociated hiPSCs (P97) and clonal hiPSCs (P89) were detected by karyotype analysis and showed that both maintained a normal 46XX chromosome complement (Fig. S2). These results demonstrated that dissociated hiPSCs and clonal hiPSCs can maintain their undifferentiated characteristics and chromosomal stability.

\section{Differentiation and identification of hiPSC-RPE cells}

Because a prerequisite for hiPSC differentiation is shutdown of the self-renewal machinery, dissociated hiPSCs were pretreated in E7 medium without FGF2 for 2 days to encourage spontaneous differentiation. FGF2 withdrawal from the culture medium may promote neuro-ectoderm induction [44], and RPE cells belong to neuro-ectoderm lineages. Therefore, the dissociated hiPSCs were switched into Proneural medium with the sequential addition of defined factors at specific time points. The differentiated cells were mechanically enriched and passaged for further experiments. A schematic illustration of the process is displayed in Fig. 1A.

Both clonal and dissociated hiPSCs grew very well. The nucleoplasmic relation of the dissociated hiPSCs became lower on day 0 , and the epithelial morphology cells began to appear on day 8 . The epithelioid-like cell monolayer was formed on day 14. RPE-like (epithelioid-like) cells were mechanically enriched, passaged, and reached $100 \%$ confluence on day 20 (Fig. 1B). Immunofluorescence assays were used to characterize the expression of RPE specific biomarkers in the enriched hiPSC-RPE cells (P1). The results showed that the hiPSC-RPE cells strongly expressed CRALBP, Mitf, Tyrosinase, Otx2, EMMPRIN, and RPE65 (Fig. 1C). RT-PCR showed the gene expressions of RPE-65, EMMPRIN, Otx2, and CRALBP but not these 
of Nanog, Oct4, Sox2, Klf4, or Lin28 in both the hiPSC-RPE and hRPE cells. In contrast, the hiPSCs expressed Nanog, Oct4, Sox2, and KIf4 but not RPE-65, EMMPRIN, Otx2, or CRALBP (Fig. 1D).

Meanwhile, western blotting showed that hiPSC-RPE cells also expressed RPE specific proteins such as RPE-65, CRALBP, EMMRPIN, Mitf, Otx2, and Tyrosinase but not Nanog, Oct4, Sox2, or Klf4. This pattern of marker protein expressions was opposite to that of hiPSCs but was similar to that seen in hRPE cells (Fig. $2 A)$. The examination of representative flow cytometry histograms revealed that hiPSC-RPE cells expressed low levels of Oct4 (2.1\%) and Sox2 (2.0\%) but expressed high levels of RPE-65 (74.4\%), CRALBP (97.4\%), Mitf (86.8\%), and EMMPRIN (93.8\%). These properties were similar to those of hRPE cells, which expressed Oct4 (1.9\%), Sox2 (1.7\%), RPE-65 (84.2\%), CRALBP (100\%), Mitf (94.2\%), and EMMRPIN (95.2\%). hiPSCs showed high levels of Oct4 (99.9\%) and Sox2 (99.9\%), but low levels of RPE65 (4.5\%), CRALBP (1.7\%), Mitf (0.4\%), and EMMRPIN (4.1\%) (Fig. 2B).

AFM was used to investigate the topography and deflection error morphologies in 2D and 3D of hiPSC, hiPSC-RPE, and hRPE cells on the cell surface and in the cell nucleus. AFM images of hiPSCs in the cells displayed a volcano-like distribution. The cell surface of the hiPSCs was relative rough, and the cell nucleus showed an oval shape. AFM image of hiPSC-RPE in the cells revealed a pancake-like configuration, which was similar to that of the hRPE. The cell surface of the hiPSC-RPE was relatively smooth, and the cell nucleus displayed a cobblestone-like appearance. The nucleo-cytoplasmic ratio of the hiPSCs was higher than that of hiPSC-RPE and hRPE (Fig. 2C and S3A). Statistical analysis showed that cell length, width, and height parameters of hiPSC-RPE cells were similar to those of hRPE cells ( ${ }^{\#} P>0.05$ ) but were different from those of hiPSCs $\left({ }^{*} P<0.05\right)$ (Fig. S3B). At the same time, the cell nucleus length, width, and height parameters of hiPSC-RPE cells were similar to those of hRPE cells $\left({ }^{\#} P>0.05\right)$ but were different from those of hiPSCs $\left({ }^{*} P<0.05\right)$ (Fig. S3C).

Taken together, these results illustrated that our protocol is able to efficiently differentiate hiPSCs into RPE-like cells and that the morphology of hiPSC-RPE cells was similar to that of hRPE cells but was different from that of hiPSCs.

\section{Maintenance of native RPE function in hiPSC-RPE cells}

One of the most important properties of RPE cells is the barrier function created by tight junctions. Tight junctions encircle each cell to form the occluding seal monolayers that retard diffusion across the paracellular space [45]. Cytoplasmic anchor protein ZO-1 is often used to establish tight junctions. Zstack confocal microscopy revealed that ZO-1 showed strong expression on the apical side of both hRPE and hiPSC-RPE cells (Fig. 3A). This polarized expression of ZO-1 is in accordance with previous reports $[34,46]$. An essential function of RPE cells is phagocytosis of outer segments shed from photoreceptors. To test whether hiPSC-RPE cells had phagocytosis function, both hRPE and hiPSC-RPE cells were incubated with FITC-POS, fixed, and then stained for ZO-1. The results showed that FITC-POS particles were specifically engulfed by cells, and extensively distributed into the cytoplasm of hiPSC-RPE and hRPE cells (Fig. 3B), indicating that these cells were capable of phagocytosis. Fluorescein leakage test (FLT) 
results showed that hiPSC-RPE cells had similar FLT values with hRPE cells at 4, 12, 24, and $36 \mathrm{~h}$ (Fig. 3C).

In addition, a transepithelial electrical resistance (TEER) assay was conducted to assess the barrier behavior of the hRPE and hiPSC-RPE cells. The data showed that the value of TEER in hRPE is 129.31.4 $\Omega$ $\mathrm{cm} 2$, and in hiPSC-RPE it is $127.11 .1 \Omega \mathrm{cm}^{2}$, but there was no significant difference between them ( $\left.{ }^{P}>0.05\right)$ (Fig. 3D).

Taken together, these results demonstrated that hiPSC-RPE cells had RPE-like functions such as forming a barrier, phagocytic activity, and a polarized membrane.

\section{Seeding of hiPSC-RPE cell spheroids in vitro}

To determine whether hiPSC-RPE cell spheroids remained viable after in vivo transplantation, we performed in vitro simulation experiments in which hiPSC-RPE cell spheroids were seeded on DCM. The porcine lamellar corneal matrix with the thickness of $100 \mu \mathrm{m}$ and the diameter of $9.29 \pm 0.24 \mathrm{~mm}$ was produced using a microkeratome (Fig. S4A). The frozen DCM and normal cornea (control) were cut to obtain tissue sections for DAPI and H\&E staining. The results showed that the DCM had almost no cells in it, but the control cornea had many cells in the epithelial and stroma layers (Fig. S4B).

$3 \mathrm{D}$ agarose molds containing eighty-one wells were produced using the commercially available silicone concave microwells. These molds were used to generate hiPSC-RPE cell spheroids (Fig. S4C). hiPSC-RPE cell spheroids were harvested and seeded onto the DCM. Inverted light microscopy imaging showed that proliferating epithelial-like hiPSC-RPE cells could migrate from the periphery of adherent cell spheroids. On day 14, hiPSC-RPE cell spheroids had disappeared and instead formed an epithelioid-like monolayer that completely covered the DCM (Fig. 4A). A live/dead assay was performed to assess the viability of hiPSC-RPE cells cultured on the DCM. On day 0 , cells in hiPSC-RPE cell spheroids were viable, showing green fluorescence by Calcein AM staining. Red fluorescence indicated dead cells by EthD-III staining. After 7 days, the majority of cells were stained by green fluorescence, and a limited number of dead cells were located mainly in the center of hiPSC-RPE cell spheroids, showing red fluorescence. On day 14, cell spheroids had disappeared, and the remaining monolayer cells were only stained by green fluorescence (Fig. 4B). Meanwhile, double immunofluorescence staining showed that the monolayer hiPSC-RPE cells cultured on the DCM expressed Occludin, Mitf, ZO-1, and RPE-65 (Fig. 4C).

In addition, hiPSC-RPE cells were stained by SA- $\beta$-Gal to determine the proportion of senescent cells. A blue color indicates the presence of SA- $\beta$-Gal staining. Positive staining of SA- $\beta-G$ al was detected in spheroids or conventional cultured hiPSC-RPE cells on days 7 and 14 (Fig. 4D). Statistical analysis of SA$\beta$-Gal staining revealed that the percentages of positive staining cells in spheroid or conventional culture hiPSC-RPE cells were $8.01 \pm 0.44 \%$ and $22.47 \pm 0.75 \%$ on day 7 , respectively. The senescent cells in the spheroid culture hiPSC-RPE cells were lower at $14.46 \pm 0.32 \%$ than those in the conventional culture hiPSCRPE cells ( $\left.{ }^{\star \star} P<0.01\right)$ (Fig. 4E). After 14 days, the cell spheroids had disappeared, and there were $15.23 \pm 0.61 \%$ senescent cells in the spheroid culture hiPSC-RPE cells and $68.68 \pm 1.34 \%$ in the 
conventional culture hiPSC-RPE cells. There was a $53.38 \pm 0.95 \%$ increase in senescence in the conventional culture hiPSC-RPE cells compared with the spheroid culture hiPSC-RPE cells $\left({ }^{\star \star} P<0.01\right)$ (Fig. $4 \mathrm{E})$. Furthermore, western blotting showed that hiPSC-RPE cells in a spheroid culture could express Nestin, which was not expressed in hiPSC-RPE cells in conventional culture (Fig. 4F); Nestin is a neural progenitor cell marker.

In our study, we reported a method to produce hiPSC-RPE cell spheroids using agarose multiwell dishes. hiPSC-RPE cell spheroids are able to maintain an integrated monolayer epithelioid morphology as well as viability after being injected onto DCM. Spheroid culture could enhance the viability of hiPSC-RPE cells, which will lay the foundation for hiPSC-RPE cell spheroid transplantation in vivo.

\section{Preliminary test of hiPSC-RPE cell spheroidsin vivo}

To evaluate the states of transplanted cells in vivo, hiPSC-RPE cell spheroids were labeled with lipophilic red dye (PKH26), which can display red fluorescence (Fig. S5A). The classical external approach for RPE transplantation was conducted to inject hiPSC-RPE cell spheroids into the upper temporal region of the equator in rabbit eyeballs (Fig. S5B). A schematic of the external approach cell transplantation is shown in Fig. S5C.

ERG provides a gross measure of light-mediated trans-retinal function. Improved retinal function was documented by scotopic ERG recordings using the Roland Retiport (RETI-Port/Scan 21) system (Fig. 5A). The results showed that photopic (light-adapted at $0.1,1,10 \mathrm{~cd} . \mathrm{s} / \mathrm{m}^{2}$ ) responses were reduced in the group that received $\mathrm{NaIO}_{3}$ in comparison with control. After one month of sub-retinal transplantation, a small functional ERG response was observed in $\mathrm{NaIO}_{3}$-hiPSC-RPE group compared with $\mathrm{NaIO}_{3}+\mathrm{PBS}$ group, which was unresponsive under similar excitation (Fig. 5B). Additionally, mean b-wave amplitudes of different groups in response to white flashes of increasing intensity after dark adaptation were statistically analyzed. The results showed that control group had distinct b-wave amplitudes, which were higher than those of other groups, but both $\mathrm{NaIO}_{3}$ and $\mathrm{NaIO}_{3}+\mathrm{PBS}$ groups almost had no b-wave amplitudes, and had no differences with each other. In addition, $\mathrm{NaIO}_{3}$ +hiPSC-RPE group could acquire partial b-wave amplitudes (Fig. 5C).

One month after transplantation, H\&E staining showed that control group had a complete RPE layer, but the RPE layers in $\mathrm{NaIO}_{3}$ and $\mathrm{NaIO}_{3}+$ PBS groups were almost totally degenerated, and a segmental sheet growth RPE layer was observed in $\mathrm{NaIO}_{3}$ thiPSC-RPE group (Fig. 6A). The immunocytochemistry assay showed that a specific marker of human cells (AHNA) could not be detected in control, $\mathrm{NaIO}_{3}$, and $\mathrm{NaIO}_{3}+\mathrm{PBS}$ groups, but was positive in $\mathrm{NaIO}_{3}$ +hiPSC-RPE group. Meanwhile, cells tagged with $\mathrm{PKH} 26$ could not be observed in in control, $\mathrm{NaIO}_{3}$, and $\mathrm{NaIO}_{3}+\mathrm{PBS}$ groups, but could be detected in $\mathrm{NaIO}_{3}+$ hiPSCRPE group (Fig. 6B).

These results demonstrated that hiPSC-RPE cell spheroids injected into the subretina of RPE degenerated chinchilla rabbits could survive for at least one month, maintain segmental sheet growth, and partially 
recover the visual function.

\section{Discussion}

The retina is a sensor and processor of visual information. Retinal damage can cause permanent loss of vision. However, recent studies in regenerative medicine have aroused hope for rescuing visual function. One of the strategies for treatment of retinal diseases is the transplantation of retinal cells, especially RPE. Partial recovery of visual function by replacement of RPE cells has been reported [47-49].

Due to the limited resources of donor cells, RPE cells derived from stem cells, especially ESCs and iPSCs, are required. In the field of ophthalmology, great progress has been made in research on iPSC differentiation. Currently, iPSCs can be successfully differentiated into corneal epithelial cells (CECs) [50, 51], eye trabecular reticular cells [52], rod cells [53], retinal progenitor cells [54, 55], RPE [56], and so on [23]. Brandl $\mathrm{C}$ et al. documented that adult dermal fibroblasts can serve as a valuable resource for iPSCRPE with characteristics highly reminiscent of RPE cells [57].

Usually, the process of differentiation of iPSCs into RPE is time consuming and has a low efficiency. The survival rate of transplanted iPSC-RPE cells in vivo is not high $[10,58,59]$. Recently, Buchholz et al. reported that iPSCs induced with a series of small molecules such as IGF-1, Noggin, DKK-1, Nicotinamide, bFGF, Activin A, SU5402, and VIP could be rapidly differentiated into RPE phenotype cells after only 14 days [60]. In our study, we modified the differentiation method proposed by Buchholz et al. Non-colony dissociated hiPSCs instead of clonal hiPSCs were pretreated with E7 iPS culture medium without bFGF for 2 days to inhibit proliferation and promote differentiation [59]. RPE-like cells began to appear on day 8 and formed a cell monolayer after removal of the dead cells through changing the medium on day 14 . Our results showed that the percentage of CRALBP ${ }^{+}$cells among the hiPSC-RPE could reach $97.4 \%$.

Usually, an RPE subpopulation with divergent morphology can be partially separated by selective trypsinization of calcium-dependent adhesion [61]. In our study, RPE-like cells were digested using $0.25 \%$ EDTA instead of trypsin to reduce any damage to their calcium-dependent adhesion. Generally, RPE cells tend to undergo morphological changes post passaging due to epithelial-mesenchymal transition (EMT) [62-64]. The tight junction of cells is vital to maintain epithelial morphology and restrain EMT occurrence [65]. In this study, hiPSC-RPE cells could retain their epithelial morphology and barrier function as shown by Matrigel and Activin-A (MA) treatment based on our previous study [37]. Their morphological features showed that hiPSC-RPE cells were similar to hRPE cells but not hiPSCs. In addition, hiPSC-RPE cells could express ZO-1 in relation to tight junctions. hiPSC-RPE cells had similar functions to hRPE cells in term of barrier and phagocytosis activity. Taken together, hiPSC-RPE cells in our study possessed normal morphology and functioned like RPE cells. Kokkinaki et al. also demonstrated that iPS-RPE could exhibit ion transport, membrane potential, and gene expression patterns similar to native RPEs [66].

Recent advances in cell culture research have shown that 3D cultures can bridge the gap between cell culture ex vivo and live tissue in vivo. Cells cultured in the 3D environment could generate many 
differences in cell behaviors and characteristics compared with that in the conventional 2D environment [67]. Cell-to-cell and cell-to-matrix interactions are maintained, and the stemness of progenitor cells can be enhanced in the 3D spheroid microenvironment [68]. 3D spheroid cultures can form distinct ECMs and establish new ECM interactions to improve cell viability and influence cell fate [69-71]. Bayoussef et al. documented that spheroid muscle cells exhibited higher proliferation capacity [25].

There are many approaches to generating cell spheroids including centrifugation, pellet culture, hanging drop culture, spinner or rotary dynamic culture systems, and so on $[72,73]$. Hanging drop or pipetting cells into multiwell plates are time consuming and laborious approaches. The generation of cell spheroids in a suspension culture in non-adhesive culture vessels results in a lack of homogeneity [72]. Here, we reported another method to produce hiPSC-RPE cell spheroids using commercially available agarose multiwell dishes. Cell spheroids with the uniform size could be quickly formed at the bottom of the nonadhesive agarose microwells. The agarose multiwell dishes easily allowed for the simultaneous generation of hundreds of homogenous hiPSC-RPE cell spheroids.

The progenies derived from cell spheroids showed only limited staining for the senescence marker SA- $\beta$ Gal, had a regular morphology, and grew at a higher density compared with passaged CECs [74]. Shortterm spheroid formation of adipose-derived stem cells (ASCs) before monolayer culture could enhance their properties of stemness, angiogenesis, and chemotaxis. ASCs derived-cell spheroids exhibited higher expansion efficiency with less senescence including SA- $\beta$-Gal staining and p21 expression [75]. In our study, SA- $\beta$-Gal staining assays showed that spheroid cultures could reduce cell senescence in hiPSCRPE, and hiPSC-RPE cell spheroids could positively express Nestin, which is a major intermediate filament protein of embryonic central nervous system progenitor cells. Expression of "progenitors" marker Nestin revealed a distinct molecular reprogramming of the cells into a stem cell state [76].

The polarized monolayer RPE cells have a basal side adherent to the Bruch's membrane (BM), which consists of 2-4 $\mu \mathrm{m}$ acellular extracellular matrix (ECM) complexes among which collagen forms a major component. The collagenous layer is composed of collagen type I, III, and V fibrils. The collagen grid is embedded in a mass of interacting biomolecules, such as glycosaminoglycans (chondroitin sulfate, dermatan sulfate, and hyaluronic acid) and components of the coagulation and complement system [77]. To better observe the monolayer growth of hiPSC-RPE cell spheroids in vitro, we used DCM as a BM substitute. DCM has a similar structure to BM but the former is more convenient to manipulate and observe. DCM is also comprised of aligned arrays of hydrated type I/V collagen fibrils, glycosaminoglycan, keratin sulfate, and dermatan sulfate [78]. An experiment of cell spheroids seeded on the DCM in vitro were used to assess the state of cells, which might offer some useful experiences for transplantation in vivo.

Huang et al. reported that cells from dermal papilla (DP) spheroids were able to maintain their structural integrity and cellular viability after an in vitro simulation experiment of the injectability of DP spheroids on culture plates [51]. As a natural ECM biomaterial, DCM is easier to obtain and is more suitable for observing cell attachment and migration [26]. Our results showed that hiPSC-RPE cells could migrate 
from the periphery of adherent cell spheroids and grow into the confluent monolayer on the DCM in vitro over 14 days when incubated with the ROCK inhibitor Y-27632. hiPSC-RPE cell spheroids maintained high cell viability for transplantation. Y-27632 can enhance cell adhesion, motility, and proliferation of human CEC spheroids [79]. Y-27632 treatment also allowed prostate colony cells to re-plate efficiently, increased the cloning efficiency of prostate stem cells in a prostate sphere assay, and suppressed cell dissociation induced apoptosis. Our previous study also confirmed that Y-27632 could decrease cell death inside spheroids, enhance cell proliferation in the spheroid periphery, and promote the monolayer growth of injectable B-CEC spheroids.

There are internal and external approaches for subretinal RPE transplantation. Dorey et al. reported that the internal technique was more precise while the external approach consistently resulted in a higher percentage of transplanted cells on Bruch's membrane [80]. Moreover, subretinal injection of hiPSC-RPE cells by the external approach is relatively easier and safer compared with the internal approach. Thus, we chose subretinal injection of hiPSC-RPE cells through an external approach in vivo study. One month after injection of hiPSC-RPE cell spheroids into the subretinal space of RPE degeneration chinchilla rabbits, a segmental sheet of RPE was observed in the cell transplantation eyeballs. Other studies have shown that mono- and multilayer RPEs could be formed after injection of RPE micro-aggregates into the subretinal space, and apoptotic cells were rarely seen [81]. In contrast to transplantation of dissociated cells, micro-aggregate transplantation developed in small patches in the outer segment of the neural retina, and these transplanted cells could survive and maintain their outer segments over the long-term [82]. Since the subretinal space is an immune-privileged site, the post-transplantation hiPS-RPE spheroids could survive at least one month without apparently systemic immunosuppression in our model.

It is important to explore how the anatomical preservation of photoreceptor to bipolar cell synapses correlated with the activation of retina circuits to photoreceptors as reflected by the ERG $b$ wave [83]. In rats that received sub-retinal cell transplantation, there was clear preservation of scotopic ERG b-waves [84]. In our study, the ERG results showed that the transplantation of hiPSC-RPE spheroids could partially recover the ERG responses and have mean b-wave amplitudes in RPE degenerated chinchilla rabbits. Rpe $65^{r d 12} /$ Rpe $65^{r d 12}$ mice transplanted with RPE-like cells showed significant visual recovery during a seven-month period as shown by ERG recordings [85]. In addition, our results showed that hiPSC-RPE cell spheroids tagged with PKH26 staining could survive and maintain segmental sheet growth in the subretinal space. However, there are still some limitations in that no comparison of the differences between hiPSC-RPE spheroid and hiPSC-RPE suspension transplantation was conducted in this study.

\section{Conclusion}

In conclusion, our study suggested that non-colony dissociated hiPSCs were effectively differentiated into functional RPE cells through the sequential adding defined factors but not bringing in exogenous genes. hiPSC-RPE cell spheroids maintained adherent monolayer growth on the DCM scaffold in vitro and segmental sheet growth in the subretina of RPE degenerate chinchilla rabbits in vivo. The preliminary 
hiPSC-RPE cell spheroid transplantation may offered an alternative cell transplantation method for RPE degenerative disease therapy in the future.

\section{Declarations}

\section{Acknowledgments}

Not Applicable.

\section{Author's contributions}

XLG conceived and designed this study, performed the experiments, analyzed the data, prepared figures and tables, and write the manuscript. DLZ, RLL, QLZ, and SM performed the experiments. SBT and JSC reviewed and revised the manuscript. All authors have read and approved the manuscript.

\section{Funding}

This work was supported by National Natural Science Foundation of China (No. 81701426 and 81371689), Special Funds for Major Science and Technology Projects of Guangdong Province (2015B010125007), Medical and Health Research Science and Technology Plan Project of Zhejiang Province (2018KY523), and Public Welfare Science and Technology Plan Project of Wenzhou City (Y20180097). The funders had no role in study design, data analysis, decision to publish, or preparation of the manuscript.

\section{Availability of data and materials}

The datasets used and analyzed during the current study are available from the corresponding author on reasonable request.

\section{Ethics approval and consent to participate}

This study was approved by the Human Research and Ethical Committee of Jinan University, and the procurement and use of human tissues were in compliance with the Declaration of Helsinki. Written consent was acquired from

every patient included in this research.

\section{Consent for publication}

Not applicable.

\section{Competing interests}

The authors declare that they have no competing interests. 


\section{Author Details}

${ }^{1}$ Key Laboratory for Regenerative Medicine, Ministry of Education, Jinan University, Guangzhou, China

${ }^{2}$ Center of Scientific Research, the Second Affiliated Hospital and Yuying Children's Hospital of Wenzhou Medical University, Wenzhou, China

${ }^{3}$ Eye Institute, Medical College of Jinan University, Guangzhou, China

${ }^{4}$ Aier School of Ophthalmology, Central South University, Changsha, China

\section{Abbreviations}

RPE: Retinal pigment epithelium; hiPSCs: human induced pluripotent stem cells; RT-PCR: reverse transcription-polymerase chain reaction); TEER: transepithelial electrical resistance; DCM: decellularized corneal matrixes; AMD: age-related macular degeneration; ESC: embryonic stem cells; B-CECs: bovine corneal endothelial cells; CSCs: corneal stromal cells; ADSCs: human adipose-derived stem cells; BM: Bruch's membrane; ECM: acellular extracellular matrix; CECs: corneal epithelial cells; MA: Activin-A; EMT: epithelial-mesenchymal transition.

\section{References}

1. Strauss 0: The retinal pigment epithelium in visual function. Physiological reviews 2005, 85(3):845881.

2. Schwartz SD, Hubschman J-P, Heilwell G, Franco-Cardenas V, Pan CK, Ostrick RM, Mickunas E, Gay R, Klimanskaya I, Lanza R: Embryonic stem cell trials for macular degeneration: a preliminary report. Lancet 2012, 379(9817):713-720.

3. Regent F, Morizur L, Lesueur L, Habeler W, Plancheron A, M'Barek KB, Monville C: Automation of human pluripotent stem cell differentiation toward retinal pigment epithelial cells for large-scale productions. Scientific reports 2019, 9(1):1-11.

4. Coffey P, Girman S, Wang S, Hetherington L, Keegan D, Adamson P, Greenwood J, Lund R: Long-term preservation of cortically dependent visual function in RCS rats by transplantation. Nature neuroscience 2002, 5(1):53-56.

5. Tezel TH, Del Priore LV, Berger AS, Kaplan HJ: Adult retinal pigment epithelial transplantation in exudative age-related macular degeneration. American journal of ophthalmology 2007, 143(4):584595. e582.

6. Gabrielian K, Oganesian A, Patel SC, Verp MS, Ernest JT: Cellular response in rabbit eyes after human fetal RPE cell transplantation. Graefes archive for clinical and experimental ophthalmology 1999, 237(4):326-335. 
7. Francis PJ, Wang S, Zhang Y, Brown A, Hwang T, McFarland TJ, Jeffrey BG, Lu B, Wright L, Appukuttan B: Subretinal transplantation of forebrain progenitor cells in nonhuman primates: survival and intact retinal function. Investigative ophthalmology \& visual science 2009, 50(7):34253431.

8. Inoue Y, Iriyama A, Ueno S, Takahashi H, Kondo M, Tamaki Y, Araie M, Yanagi Y: Subretinal transplantation of bone marrow mesenchymal stem cells delays retinal degeneration in the RCS rat model of retinal degeneration. Experimental eye research 2007, 85(2):234-241.

9. Wang S, Girman S, Lu B, Bischoff N, Holmes T, Shearer R, Wright LS, Svendsen CN, Gamm DM, Lund RD: Long-term vision rescue by human neural progenitors in a rat model of photoreceptor degeneration. Investigative ophthalmology \& visual science 2008, 49(7):3201-3206.

10. Klimanskaya I, Hipp J, Rezai KA, West M, Atala A, Lanza R: Derivation and comparative assessment of retinal pigment epithelium from human embryonic stem cells using transcriptomics. Cloning and stem cells 2004, 6(3):217-245.

11. Iwasaki Y, Sugita S, Mandai M, Yonemura S, Onishi A, Ito S-i, Mochizuki M, Ohno-Matsui K, Takahashi M: Differentiation/Purification Protocol for Retinal Pigment Epithelium from Mouse Induced Pluripotent Stem Cells as a Research Tool. PloS one 2016, 11(7):e0158282.

12. Maruotti J, Sripathi SR, Bharti K, Fuller J, Wahlin KJ, Ranganathan V, Sluch VM, Berlinicke CA, Davis J, Kim C: Small-molecule-directed, efficient generation of retinal pigment epithelium from human pluripotent stem cells. Proceedings of the National Academy of Sciences 2015, 112(35):1095010955.

13. Maruotti J, Wahlin K, Gorrell D, Bhutto I, Lutty G, Zack DJ: A simple and scalable process for the differentiation of retinal pigment epithelium from human pluripotent stem cells. Stem cells translational medicine 2013, 2(5):341-354.

14. Chen KG, Mallon BS, Hamilton RS, Kozhich OA, Park K, Hoeppner DJ, Robey PG, McKay RD: Noncolony type monolayer culture of human embryonic stem cells. Stem Cell Res 2012, 9(3):237-248.

15. Chen KG, Mallon BS, McKay RD, Robey PG: Human pluripotent stem cell culture: considerations for maintenance, expansion, and therapeutics. Cell Stem Cell 2014, 14(1):13-26.

16. Guo X, Lian R, Guo Y, Liu Q, Ji Q, Chen J: bFGF and Activin A function to promote survival and proliferation of single iPS cells in conditioned half-exchange mTeSR1 medium. Hum Cell 2015, 28(3):122-132.

17. Diniz B, Thomas P, Thomas B, Ribeiro R, Hu Y, Brant R, Ahuja A, Zhu D, Liu L, Koss M: Subretinal implantation of retinal pigment epithelial cells derived from human embryonic stem cells: improved survival when implanted as a monolayer. Investigative ophthalmology \& visual science 2013, 54(7):5087-5096.

18. M'Barek KB, Habeler W, Plancheron A, Jarraya M, Regent F, Terray A, Yang Y, Chatrousse L, Domingues $S$, Masson Y: Human ESC-derived retinal epithelial cell sheets potentiate rescue of photoreceptor cell loss in rats with retinal degeneration. Science translational medicine 2017, 9(421):eaai7471. 
19. da Cruz L, Fynes K, Georgiadis O, Kerby J, Luo YH, Ahmado A, Vernon A, Daniels JT, Nommiste B, Hasan SM et al: Phase 1 clinical study of an embryonic stem cell-derived retinal pigment epithelium patch in age-related macular degeneration. Nat Biotechnol 2018, 36(4):328-337.

20. Davis RJ, Alam NM, Zhao C, Muller C, Saini JS, Blenkinsop TA, Mazzoni F, Campbell M, Borden SM, Charniga CJ et al: The Developmental Stage of Adult Human Stem Cell-Derived Retinal Pigment Epithelium Cells Influences Transplant Efficacy for Vision Rescue. Stem Cell Reports 2017, 9(1):4249.

21. Kashani AH, Lebkowski JS, Rahhal FM, Avery RL, Salehi-Had H, Dang W, Lin CM, Mitra D, Zhu D, Thomas BB et al: A bioengineered retinal pigment epithelial monolayer for advanced, dry age-related macular degeneration. Sci Trans/ Med 2018, 10(435).

22. May-Simera HL, Wan Q, Jha BS, Hartford J, Khristov V, Dejene R, Chang J, Patnaik S, Lu Q, Banerjee P et al: Primary Cilium-Mediated Retinal Pigment Epithelium Maturation Is Disrupted in Ciliopathy Patient Cells. Cell Rep 2018, 22(1):189-205.

23. Stern JH, Tian Y, Funderburgh J, Pellegrini G, Zhang K, Goldberg JL, Ali RR, Young M, Xie Y, Temple S: Regenerating Eye Tissues to Preserve and Restore Vision. Cell Stem Cell 2018, 22(6):834-849.

24. Huang YC, Chan CC, Lin WT, Chiu HY, Tsai RY, Tsai TH, Chan JY, Lin SJ: Scalable production of controllable dermal papilla spheroids on PVA surfaces and the effects of spheroid size on hair follicle regeneration. Biomaterials 2013, 34(2):442-451.

25. Bayoussef Z, Dixon JE, Stolnik S, Shakesheff KM: Aggregation promotes cell viability, proliferation, and differentiation in an in vitro model of injection cell therapy. Journal of tissue engineering and regenerative medicine 2012, 6(10):e61-e73.

26. Guo Y, Liu Q, Yang Y, Guo X, Lian R, Li S, Wang C, Zhang S, Chen J: The effects of ROCK inhibitor Y27632 on injectable spheroids of bovine corneal endothelial cells. Cellular Reprogramming 2015, 17(1):77-87.

27. Li H, Dai Y, Shu J, Yu R, Guo Y, Chen J: Spheroid cultures promote the stemness of corneal stromal cells. Tissue and Cell 2015, 47(1):39-48.

28. Schwartz SD, Regillo CD, Lam BL, Eliott D, Rosenfeld PJ, Gregori NZ, Hubschman J-P, Davis JL, Heilwell G, Spirn M: Human embryonic stem cell-derived retinal pigment epithelium in patients with age-related macular degeneration and Stargardt's macular dystrophy: follow-up of two open-label phase 1/2 studies. Lancet 2015, 385(9967):509-516.

29. Mandai M, Watanabe A, Kurimoto Y, Hirami Y, Morinaga C, Daimon T, Fujihara M, Akimaru H, Sakai N, Shibata Y: Autologous induced stem-cell-derived retinal cells for macular degeneration. New England Journal of Medicine 2017, 376(11):1038-1046.

30. Westenskow PD, Bucher F, Bravo S, Kurihara T, Feitelberg D, Paris LP, Aguilar E, Lin JH, Friedlander M: iPSC-Derived Retinal Pigment Epithelium Allografts Do Not Elicit Detrimental Effects in Rats: A Follow-Up Study. Stem Cells Int 2016, 2016:8470263.

31. Amirpour N, Karamali F, Rabiee F, Rezaei L, Esfandiari E, Razavi S, Dehghani A, Razmju H, NasrEsfahani MH, Baharvand $\mathrm{H}$ : Differentiation of human embryonic stem cell-derived retinal 
progenitors into retinal cells by sonic hedgehog and/or retinal pigmented epithelium and transplantation into the subretinal space of sodium iodate-injected rabbits. Stem cells and development 2012, 21(1):42-53.

32. Moriguchi M, Nakamura S, Inoue Y, Nishinaka A, Nakamura M, Shimazawa M, Hara H: Irreversible photoreceptors and RPE cells damage by intravenous sodium iodate in mice is related to macrophage accumulation. Investigative ophthalmology \& visual science 2018, 59(8):3476-3487.

33. Zhao Z, Yu R, Yang J, Liu X, Tan M, Li H, Chen J: Maxadilan prevents apoptosis in iPS cells and shows no effects on the pluripotent state or karyotype. PloS one 2012, 7(3):e33953.

34. Maminishkis A, Chen S, Jalickee S, Banzon T, Shi G, Wang FE, Ehalt T, Hammer JA, Miller SS: Confluent monolayers of cultured human fetal retinal pigment epithelium exhibit morphology and physiology of native tissue. Investigative ophthalmology \& visual science 2006, 47(8):3612-3624.

35. Guo X, Yu R, Xu Y, Lian R, Yu Y, Cui Z, Ji Q, Chen J, Li Z, Liu H: PAC1R agonist maxadilan enhances hADSC viability and neural differentiation potential. Journal of cellular and molecular medicine 2016.

36. Cottin M, Zanvit A: Fluorescein leakage test: a useful tool in ocular safety assessment. Toxicology in vitro 1997, 11(4):399-405.

37. Guo X, Zhu D, Lian R, Han Y, Guo Y, Li Z, Tang S, Chen J: Matrigel and Activin A promote cell-cell contact and anti-apoptotic activity in cultured human retinal pigment epithelium cells. Experimental eye research 2016, 147:37-49.

38. Cartagena-Rivera AX, Wang W-H, Geahlen RL, Raman A: Fast, multi-frequency, and quantitative nanomechanical mapping of live cells using the atomic force microscope. Scientific reports 2015, 5:11692.

39. Krohne TU, Holz FG, Kopitz J: Apical-to-basolateral transcytosis of photoreceptor outer segments induced by lipid peroxidation products in human retinal pigment epithelial cells. Invest Ophthalmol Vis Sci 2010, 51(1):553-560.

40. Yang J, Caprioli RM: Matrix sublimation/recrystallization for imaging proteins by mass spectrometry at high spatial resolution. Analytical chemistry 2011, 83(14):5728-5734.

41. Tzameret A, Sher I, Belkin M, Treves AJ, Meir A, Nagler A, Levkovitch-Verbin H, Barshack I, Rosner M, Rotenstreich Y: Transplantation of human bone marrow mesenchymal stem cells as a thin subretinal layer ameliorates retinal degeneration in a rat model of retinal dystrophy. Experimental eye research 2014, 118:135-144.

42. Peng B, Xiao J, Wang K, So K-F, Tipoe GL, Lin B: Suppression of microglial activation is neuroprotective in a mouse model of human retinitis pigmentosa. Journal of Neuroscience 2014, 34(24):8139-8150.

43. Mi X-S, Feng Q, Lo ACY, Chang RC-C, Lin B, Chung SK, So K-F: Protection of retinal ganglion cells and retinal vasculature by Lycium barbarum polysaccharides in a mouse model of acute ocular hypertension. PLoS One 2012, 7(10):e45469. 
44. Greber B, Coulon P, Zhang M, Moritz S, Frank S, Müller-Molina AJ, Araúzo-Bravo MJ, Han DW, Pape HC, Schöler HR: FGF signalling inhibits neural induction in human embryonic stem cells. The EMBO journal 2011, 30(24):4874-4884.

45. Luo Y, Zhuo Y, Fukuhara M, Rizzolo LJ: Effects of culture conditions on heterogeneity and the apical junctional complex of the ARPE-19 cell line. Investigative ophthalmology \& visual science 2006, 47(8):3644-3655.

46. Gamm DM, Melvan JN, Shearer RL, Pinilla I, Sabat G, Svendsen CN, Wright LS: A novel serum-free method for culturing human prenatal retinal pigment epithelial cells. Investigative ophthalmology \& visual science $2008,49(2): 788-799$.

47. da Cruz L, Chen FK, Ahmado A, Greenwood J, Coffey P: RPE transplantation and its role in retinal disease. Progress in retinal and eye research 2007, 26(6):598-635.

48. Chen FK, Uppal GS, MacLaren RE, Coffey PJ, Rubin GS, Tufail A, Aylward GW, Da Cruz L: Long-term visual and microperimetry outcomes following autologous retinal pigment epithelium choroid graft for neovascular age-related macular degeneration. Clinical \& experimental ophthalmology 2009, 37(3):275-285.

49. Chen FK, Patel PJ, Uppal GS, Tufail A, Coffey PJ, Da Cruz L: Long-term outcomes following full macular translocation surgery in neovascular age-related macular degeneration. British Journal of Ophthalmology 2010, 94(10):1337-1343.

50. Hayashi R, Ishikawa Y, Ito M, Kageyama T, Takashiba K, Fujioka T, Tsujikawa M, Miyoshi H, Yamato M, Nakamura Y: Generation of corneal epithelial cells from induced pluripotent stem cells derived from human dermal fibroblast and corneal limbal epithelium. PLoS One 2012, 7(9):e45435.

51. Yu D, Chen M, Sun X, Ge J: Differentiation of mouse induced pluripotent stem cells into corneal epithelial-like cells. Cell biology internationa/ 2013, 37(1):87-94.

52. Abu-Hassan DW, Li X, Ryan El, Acott TS, Kelley MJ: Induced Pluripotent Stem Cells Restore Function in a Human Cell Loss Model of Open-Angle Glaucoma. Stem cells 2015, 33(3):751-761.

53. Boucherie C, Mukherjee S, Henckaerts E, Thrasher AJ, Sowden JC, Ali RR: Brief Report: SelfOrganizing Neuroepithelium from Human Pluripotent Stem Cells Facilitates Derivation of Photoreceptors. Stem cells 2013, 31(2):408-414.

54. Parameswaran S, Balasubramanian S, Babai N, Qiu F, Eudy JD, Thoreson WB, Ahmad I: Induced Pluripotent Stem Cells Generate Both Retinal Ganglion Cells and Photoreceptors: Therapeutic Implications in Degenerative Changes in Glaucoma and Age-Related Macular Degeneration. Stem Cells 2010, 28(4):695-703.

55. Tucker BA, Park I-H, Qi SD, Klassen HJ, Jiang C, Yao J, Redenti S, Daley GQ, Young MJ:

Transplantation of adult mouse iPS cell-derived photoreceptor precursors restores retinal structure and function in degenerative mice. PloS one 2011, 6(4):e18992.

56. Okamoto S, Takahashi M: Induction of retinal pigment epithelial cells from monkey iPS cells. Investigative ophthalmology \& visual science 2011, 52(12):8785-8790. 
57. Brandl C, Zimmermann SJ, Milenkovic VM, Rosendahl SM, Grassmann F, Milenkovic A, Hehr U, Federlin M, Wetzel $\mathrm{CH}$, Helbig $\mathrm{H}$ et al: In-depth characterisation of Retinal Pigment Epithelium (RPE) cells derived from human induced pluripotent stem cells (hiPSC). Neuromolecular Med 2014, 16(3):551-564.

58. Buchholz DE, Hikita ST, Rowland TJ, Friedrich AM, Hinman CR, Johnson LV, Clegg DO: Derivation of functional retinal pigmented epithelium from induced pluripotent stem cells. Stem cells 2009, 27(10):2427-2434.

59. Carr AJ, Vugler AA, Hikita ST, Lawrence JM, Gias C, Chen LL, Buchholz DE, Ahmado A, Smart MJ, Hasan S: Protective effects of human iPS-derived retinal pigment epithelium cell transplantation in the retinal dystrophic rat. PloS one 2009, 4(12):e8152.

60. Buchholz DE, Pennington BO, Croze RH, Hinman CR, Coffey PJ, Clegg DO: Rapid and efficient directed differentiation of human pluripotent stem cells into retinal pigmented epithelium. Stem cells translational medicine 2013, 2(5):384-393.

61. McKay BS, Burke JM: Separation of phenotypically distinct subpopulations of cultured human retinal pigment epithelial cells. Exp Cell Res 1994, 213(1):85-92.

62. Grisanti S, Guidry C: Transdifferentiation of retinal pigment epithelial cells from epithelial to mesenchymal phenotype. Investigative ophthalmology \& visual science 1995, 36(2):391-405.

63. Ganti R, Hunt RC, Parapuram SK, Hunt DM: Vitreous modulation of gene expression in low-passage human retinal pigment epithelial cells. Investigative ophthalmology \& visual science 2007, 48(4):1853-1863.

64. Lee H, O'Meara SJ, O'Brien C, Kane R: The role of gremlin, a BMP antagonist, and epithelial-tomesenchymal transition in proliferative vitreoretinopathy. Investigative ophthalmology \& visual science 2007, 48(9):4291-4299.

65. Tamiya S, Liu L, Kaplan HJ: Epithelial-mesenchymal transition and proliferation of retinal pigment epithelial cells initiated upon loss of cell-cell contact. Investigative ophthalmology \& visual science 2010, 51(5):2755-2763.

66. Kokkinaki M, Sahibzada N, Golestaneh N: Human induced pluripotent stem-derived retinal pigment epithelium (RPE) cells exhibit ion transport, membrane potential, polarized vascular endothelial growth factor secretion, and gene expression pattern similar to native RPE. Stem Cells 2011, 29(5):825-835.

67. Page H, Flood P, Reynaud EG: Three-dimensional tissue cultures: current trends and beyond. Cell and tissue research 2013, 352(1):123-131.

68. Lee WY, Wei HJ, Lin WW, Yeh YC, Hwang SM, Wang JJ, Tsai MS, Chang Y, Sung HW: Enhancement of cell retention and functional benefits in myocardial infarction using human amniotic-fluid stem-cell bodies enriched with endogenous ECM. Biomaterials 2011, 32(24):5558-5567.

69. Jensen UB, Lowell S, Watt FM: The spatial relationship between stem cells and their progeny in the basal layer of human epidermis: a new view based on whole-mount labelling and lineage analysis. Development 1999, 126(11):2409-2418. 
70. Song X, Zhu C-H, Doan C, Xie T: Germline stem cells anchored by adherens junctions in the Drosophila ovary niches. Science 2002, 296(5574):1855-1857.

71. Garcion E, Halilagic A, Faissner A: Generation of an environmental niche for neural stem cell development by the extracellular matrix molecule tenascin C. Development 2004, 131(14):3423-3432.

72. Burridge PW, Thompson S, Millrod MA, Weinberg S, Yuan X, Peters A, Mahairaki V, Koliatsos VE, Tung L, Zambidis ET: A universal system for highly efficient cardiac differentiation of human induced pluripotent stem cells that eliminates interline variability. PloS one 2011, 6(4):e18293.

73. Lin RZ, Chang HY: Recent advances in three-dimensional multicellular spheroid culture for biomedical research. Biotechnology journal 2008, 3(9-10):1172-1184.

74. Mimura T, Yamagami S, Yokoo S, Usui T, Amano S: Selective isolation of young cells from human corneal endothelium by the sphere-forming assay. Tissue Eng Part C Methods 2010, 16(4):803-812.

75. Cheng NC, Chen SY, Li JR, Young TH: Short-term spheroid formation enhances the regenerative capacity of adipose-derived stem cells by promoting stemness, angiogenesis, and chemotaxis. Stem Cells Transl Med 2013, 2(8):584-594.

76. Ranaei Pirmardan E, Soheili ZS, Samiei S, Ahmadieh H, Mowla SJ, Ezzati R, Naseri M:

Characterization of a spontaneously generated murine retinal pigmented epithelium cell line; a model for in vitro experiments. Exp Cell Res 2016, 347(2):332-338.

77. Li SY, Yin ZQ, Chen SJ, Chen LF, Liu Y: Rescue from light-induced retinal degeneration by human fetal retinal transplantation in minipigs. Curr Eye Res 2009, 34(7):523-535.

78. Ruberti JW, Zieske JD: Prelude to corneal tissue engineering - gaining control of collagen organization. Prog Retin Eye Res 2008, 27(5):549-577.

79. Bi YL, Zhou Q, Du F, Wu MF, Xu GT, Sui GQ: Regulation of functional corneal endothelial cells isolated from sphere colonies by Rho-associated protein kinase inhibitor. Exp Ther Med 2013, 5(2):433-437.

80. Wongpichedchai S, Weiter JJ, Weber P, Dorey CK: Comparison of external and internal approaches for transplantation of autologous retinal pigment epithelium. Invest Ophthalmol Vis Sci 1992, 33(12):3341-3352.

81. Wang H, Leonard DS, Castellarin AA, Tsukahara I, Ninomiya Y, Yagi F, Cheewatrakoolpong N, Sugino IK, Zarbin MA: Short-term study of allogeneic retinal pigment epithelium transplants onto debrided Bruch's membrane. Investigative ophthalmology \& visual science 2001, 42(12):2990-2999.

82. Gouras $\mathrm{P}$, Tanabe T: Survival and integration of neural retinal transplants in rd mice. Graefes Arch Clin Exp Ophthalmol 2003, 241(5):403-409.

83. Pinilla I, Cuenca N, Sauvé Y, Wang S, Lund RD: Preservation of outer retina and its synaptic connectivity following subretinal injections of human RPE cells in the Royal College of Surgeons rat. Experimental eye research 2007, 85(3):381-392.

84. Seiler MJ, Aramant RB: Cell replacement and visual restoration by retinal sheet transplants. Progress in retinal and eye research 2012, 31(6):661-687. 
85. Wang N-K, Tosi J, Kasanuki JM, Chou CL, Kong J, Parmalee N, Wert KJ, Allikmets R, Lai C-C, Chien C$\mathrm{L}$ : Transplantation of reprogrammed embryonic stem cells improves visual function in a mouse model for retinitis pigmentosa. Transplantation 2010, 89(8):911.

\section{Tables}

\section{Table 1. Primer information}




\begin{tabular}{|c|c|c|c|}
\hline Primers & Sequences ( $5^{\prime}$ to $3^{\prime}$ ) & Product length & GeneBank Number \\
\hline GADPH-F & CCACTAGGCGCTCACTGTTC & $180 \mathrm{bp}$ & NM_001289746.1 \\
\hline GADPH-R & TTGAGGTCAATGAAGGGGTCA & & \\
\hline RPE-65-F & TGACCGATTCAAGCCATCTT & $363 b p$ & NM_000329.2 \\
\hline RPE-65-R & АССTCTTCCCAGTTCTCACG & & \\
\hline Otx2-F & GGAAGGGAGGGAAGGTCATA & $343 b p$ & NM_001270523.1 \\
\hline Otx2-R & GCAGAGGTGGAGTTCAAGGT & & \\
\hline EMMPRIN-F & GCAGGTTCTTCGTGAGTTCC & $314 b p$ & NM_001728.3 \\
\hline EMMPRIN-R & GCCTTTGTCATTCTGGTGCT & & \\
\hline CRALBP-F & AAGCCATCCACTTCATCCAC & $338 b p$ & NM_000326.4 \\
\hline CRALBP-R & TCTCAAGCAGCCCTTTCCTA & & \\
\hline Nanog-F & CAAGAАСТСТССААСАТССТGАА & $126 \mathrm{bp}$ & NM_024865.2 \\
\hline Nanog-R & CCTGCGTCACACCATTGCTATTC & & \\
\hline Oct4-F & GAAGGATGTGGTCCGAGTGT & 183bp & NM_001173531.2 \\
\hline Oct4-R & GTGAAGTGAGGGCTCCCATA & & \\
\hline Sox2-F & CAGGAGTTGTCAAGGCAGAGA & $171 b p$ & NM_003106.3 \\
\hline Sox2-R & CCGCCGCCGATGATTGTTA & & \\
\hline KIf4-F & GCCGCTCCATTACCAAGAG & $166 b p$ & NM_004235.4 \\
\hline KIf4-R & GTGTGCCTTGAGATGGGAAC & & \\
\hline c-Myc-F & CATCAGCACAACTACGCAGC & $120 b p$ & NM_002467.4 \\
\hline c-Myc-R & GCTGGTGCATTTTCGGTTGT & & \\
\hline Lin28-F & CCCATCACTGGGGTGTGTTT & $162 b p$ & NM_024674.4 \\
\hline Lin28-R & CAGTTTGCGTACCAATAAGTCTTT & & \\
\hline Nestin-F & AACAGCGACGGAGGTCTCTA & $220 b p$ & NM_006617.1 \\
\hline Nestin-R & TTCTCTTGTCCCGCAGACTT & & \\
\hline Pax6-F & TGTTGCGGAGTGATTAGTGGG & 196bp & NM_000280.4 \\
\hline Pax6-R & TTGGTGATGGCTCAAGTGTGT & & \\
\hline
\end{tabular}


Table 2. Antibodies

Page 28/37 


\begin{tabular}{|c|c|c|c|c|c|c|c|}
\hline \multirow{3}{*}{$\begin{array}{l}\text { Antibody } \\
\text { b-ACTIN }\end{array}$} & \multirow{3}{*}{$\begin{array}{l}\text { Species } \\
\text { mouse }\end{array}$} & \multirow{3}{*}{$\begin{array}{l}\text { Vendor (City, State, } \\
\text { catalogue) } \\
\text { Santa Cruz (Santa Cruz, } \\
\text { CA, } \\
\text { sc-47778) }\end{array}$} & \multicolumn{3}{|c|}{ Dilution } & & \\
\hline & & & \multirow{2}{*}{$\begin{array}{l}\text { WB } \\
1: 1000\end{array}$} & \multirow{2}{*}{$\begin{array}{l}\text { IC } \\
\text { ND }\end{array}$} & \multirow[t]{2}{*}{$\mathrm{FC}$} & \multicolumn{2}{|c|}{ IF } \\
\hline & & & & & & ND & ND \\
\hline CRALBP & mouse & $\begin{array}{l}\text { Abcam (Cambridge, MA, } \\
\text { ab15051) }\end{array}$ & $1: 5000$ & ND & & $1: 100$ & $1: 350$ \\
\hline Mitf & rabbit & $\begin{array}{l}\text { Abcam (Cambridge, MA, } \\
\text { ab122982) }\end{array}$ & 1:10000 & ND & & $1: 100$ & $1: 1000$ \\
\hline Tyrosinase & rabbit & $\begin{array}{l}\text { Abcam (Cambridge, MA, } \\
\text { ab180753) }\end{array}$ & $1: 5000$ & ND & & ND & $1: 100$ \\
\hline Otx2 & mouse & $\begin{array}{l}\text { Abcam (Cambridge, MA, } \\
\text { ab130238) }\end{array}$ & $1: 5000$ & ND & & ND & $1: 500$ \\
\hline EMMPRIN & mouse & $\begin{array}{l}\text { Abcam (Cambridge, MA, } \\
\text { ab119114) }\end{array}$ & $1: 3000$ & ND & & $1: 100$ & $1: 100$ \\
\hline RPE-65 & mouse & $\begin{array}{l}\text { Abcam (Cambridge, MA, } \\
\text { ab13826) }\end{array}$ & 1:10000 & ND & & $1: 100$ & $1: 1000$ \\
\hline Nanog & rabbit & $\begin{array}{l}\text { Cell Signaling (Danvers, } \\
\text { MA, } \\
8822)\end{array}$ & 1:1000 & ND & & ND & $1: 500$ \\
\hline Oct4 & rabbit & $\begin{array}{l}\text { Cell Signaling (Danvers, } \\
\text { MA, } \\
2750 \text { ) }\end{array}$ & $1: 1000$ & ND & & $1: 100$ & $1: 100$ \\
\hline Sox2 & rabbit & $\begin{array}{l}\text { Cell Signaling (Danvers, } \\
\text { MA, } \\
3579 \text { ) }\end{array}$ & $1: 1000$ & ND & & $1: 100$ & $1: 100$ \\
\hline KIf4 & rabbit & $\begin{array}{l}\text { Cell Signaling (Danvers, } \\
\text { MA, } \\
12173 \text { ) }\end{array}$ & $1: 1000$ & ND & & ND & ND \\
\hline SSEA4 & mouse & $\begin{array}{l}\text { Cell Signaling (Danvers, } \\
\text { MA, }\end{array}$ & ND & ND & & ND & $1: 500$ \\
\hline TRA-1-60 & mouse & 4755) & ND & ND & & ND & $1: 500$ \\
\hline
\end{tabular}




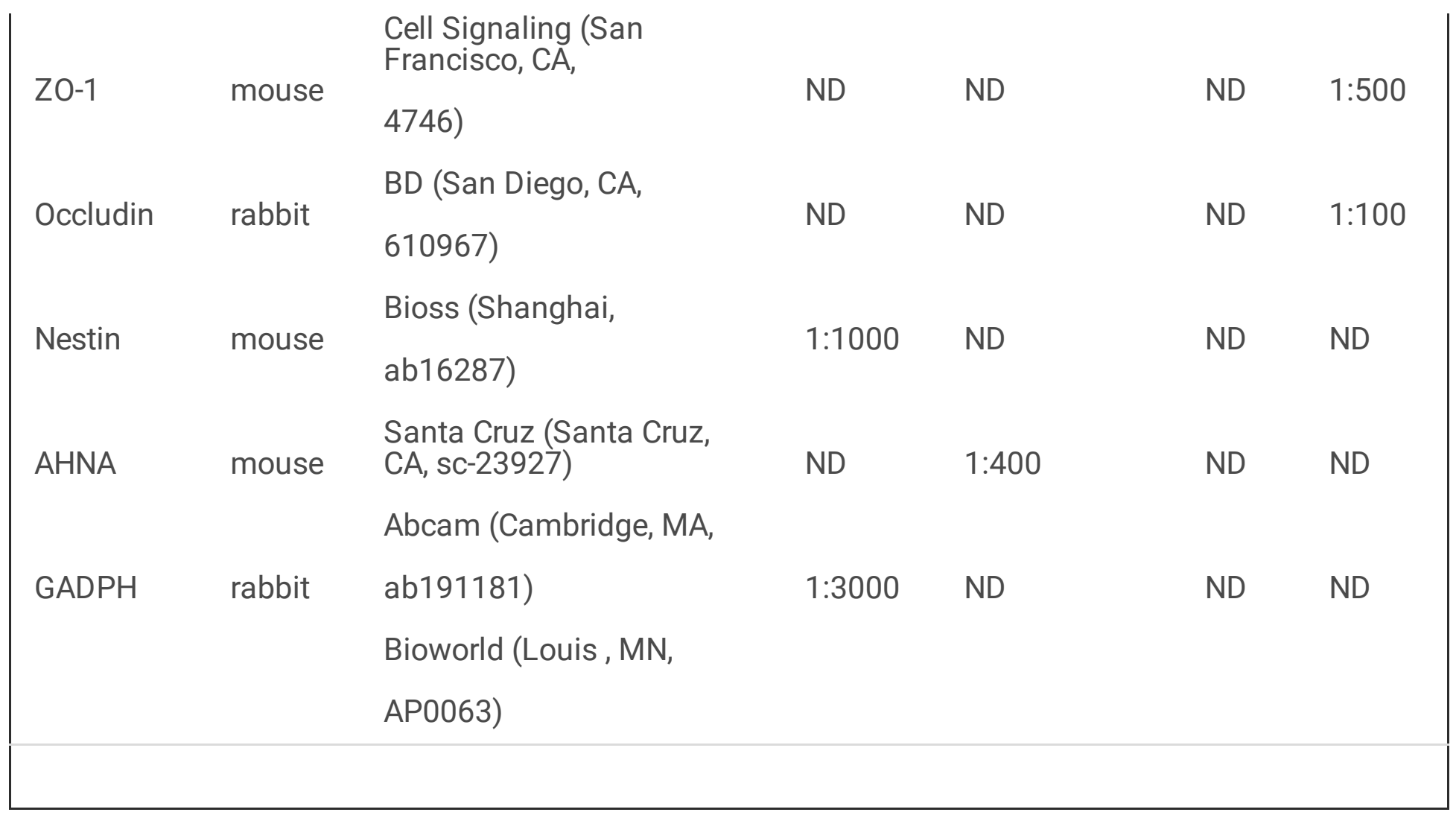

$\mathrm{ND}=$ Not detected; $\mathrm{WB}=$ Western blot; $\mathrm{IC}=$ Immunohistochemistry; FC = Flow Cyt; $\mathrm{IF}=$ Immunofluorescence.

\section{Figures}


A

$\begin{array}{llllll}\text { Aay-2 Day } 0 & \text { Day 2 } & \text { Day 4 } & \text { Day } 6 & \text { Day } 30\end{array}$

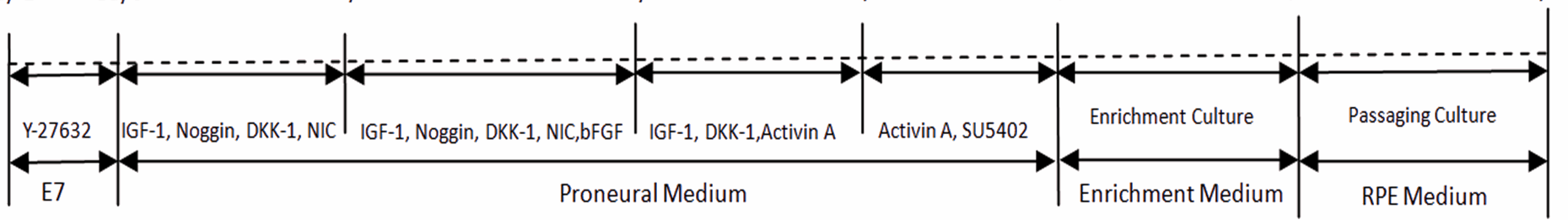

B
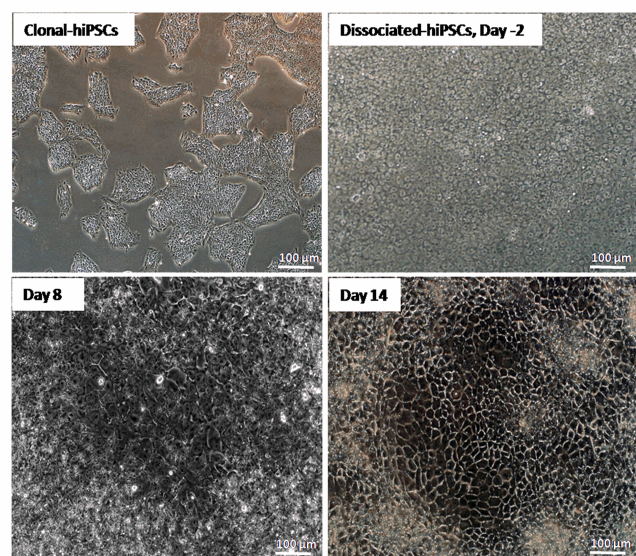

C
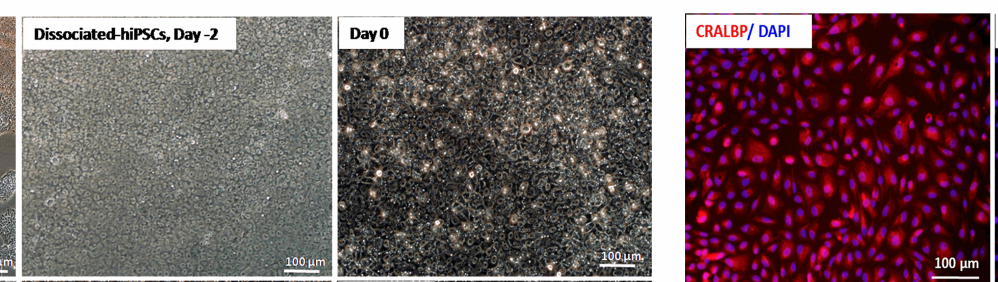

Day 30 (P1)
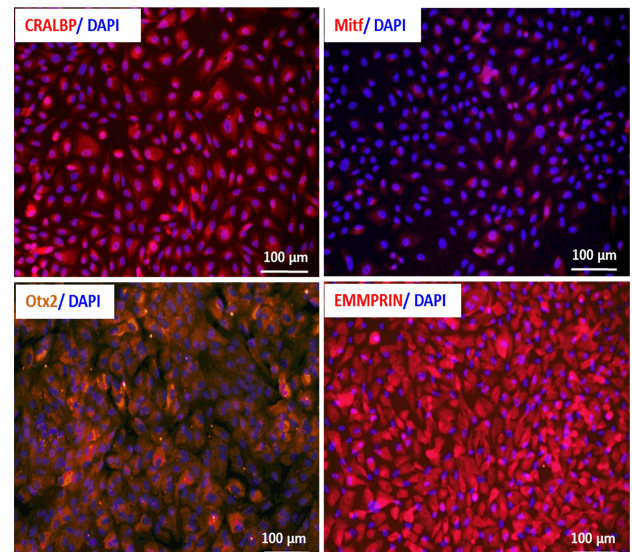

Tyrosinase/ DAPI

EMMPRIN/ DAPI

$100 \mu \mathrm{m}$
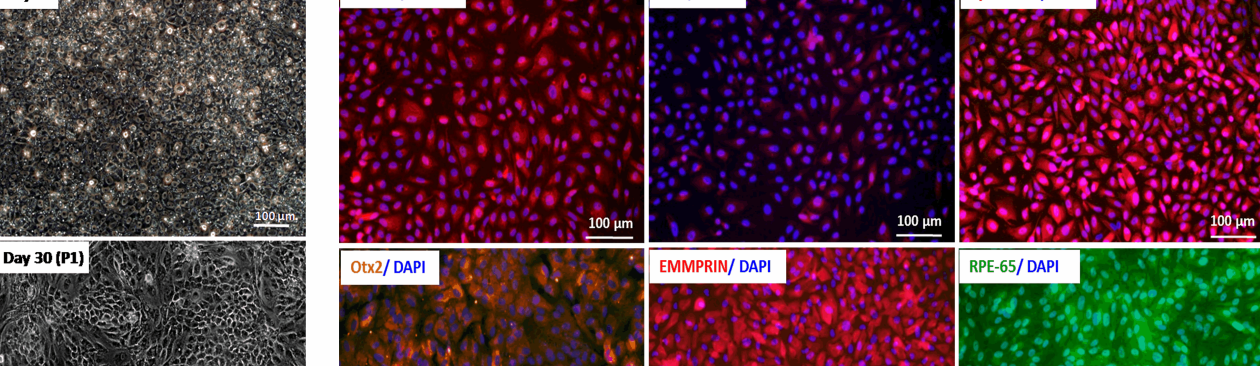

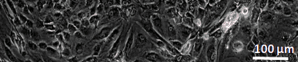

$100 \mu \mathrm{m}$

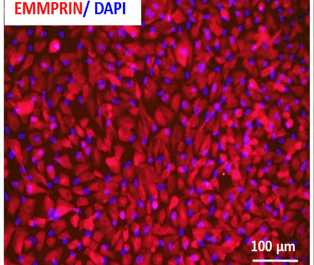

RPE-65/ DAPI

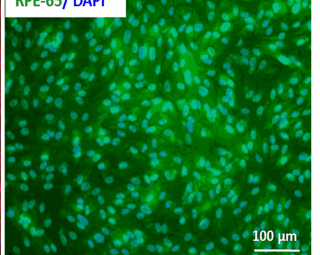

D
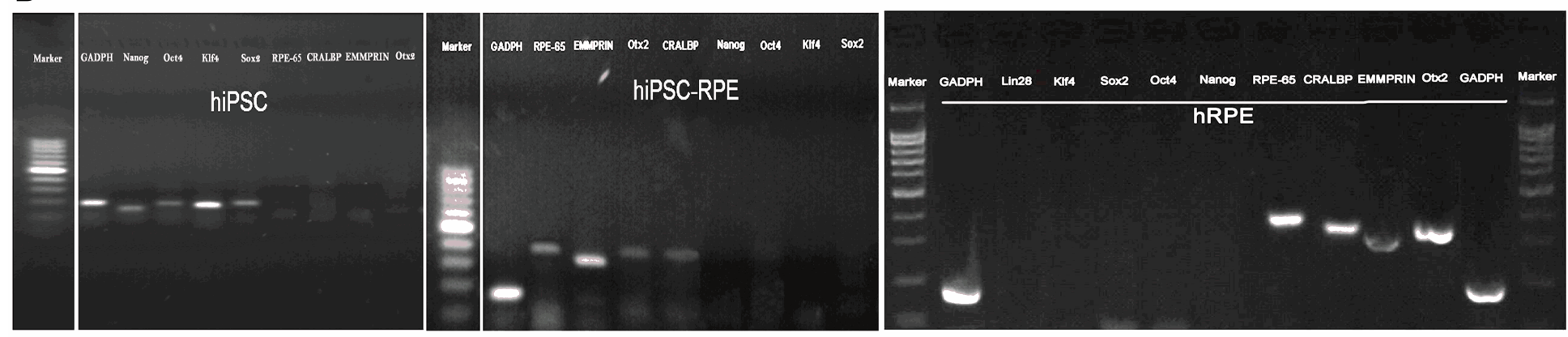

Figure 1

Differentiation and identification of hiPSC-RPE cells. (A) A schematic illustration of the differentiation protocol of the hiPSC-RPE cells. (B) Morphological changes in the differentiation of cells under an inverted microscope. (C) The identification of hiPSC-RPE cells (P1) using an immunofluorescence assay and (D) an RT-PCR assay. 


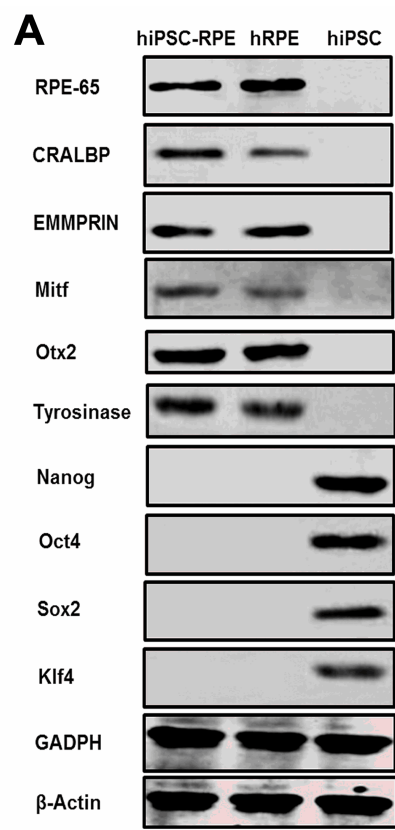

B
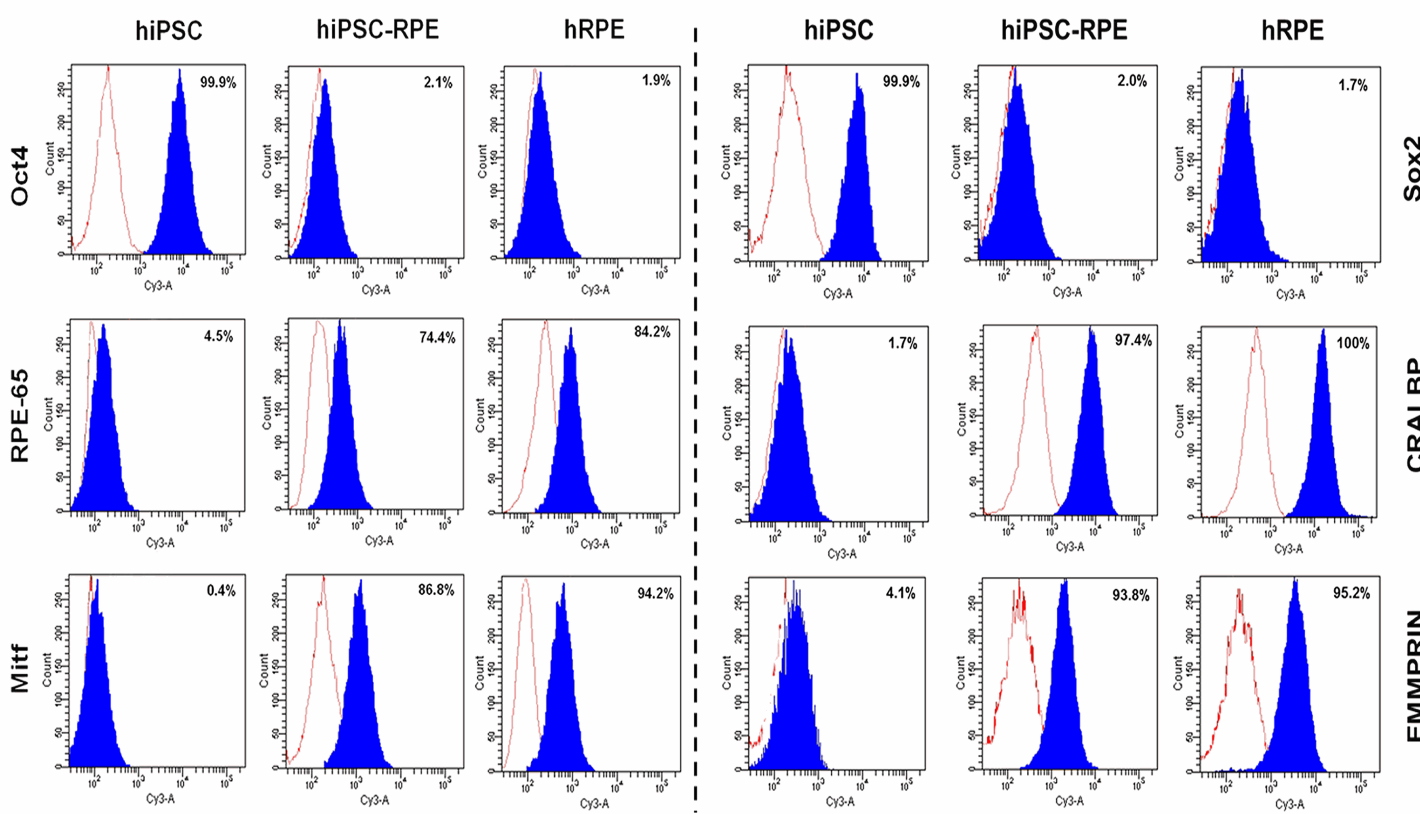

ஸ̃

C hiPSCs

hiPSC-RPE
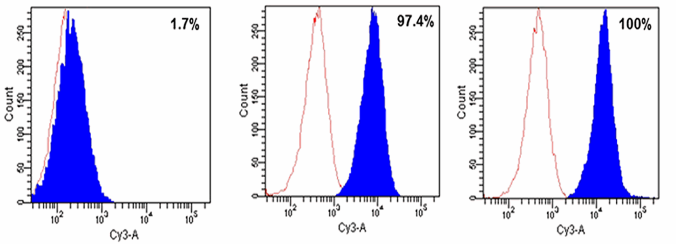

$\frac{0}{m}$
$\frac{1}{\sigma}$
$\frac{0}{0}$
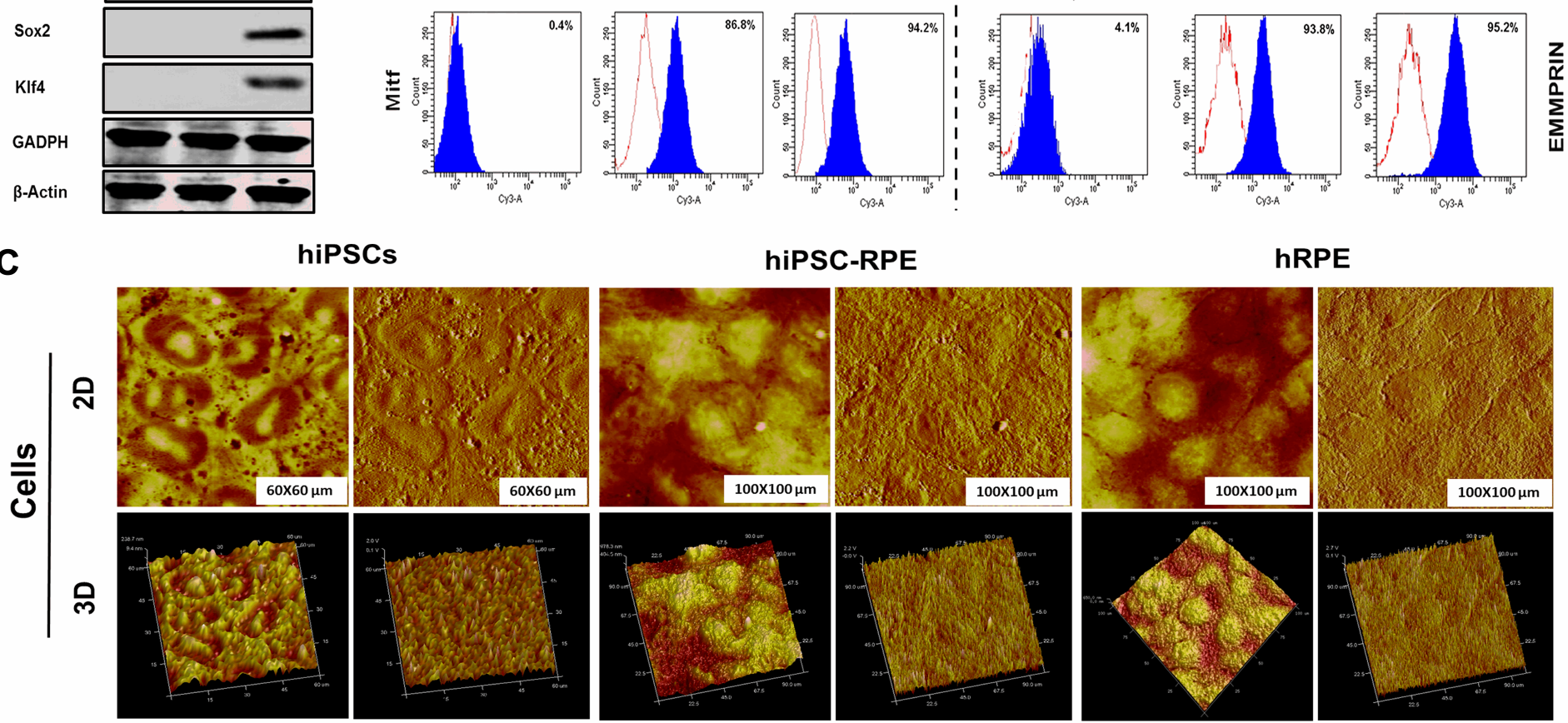

hRPE
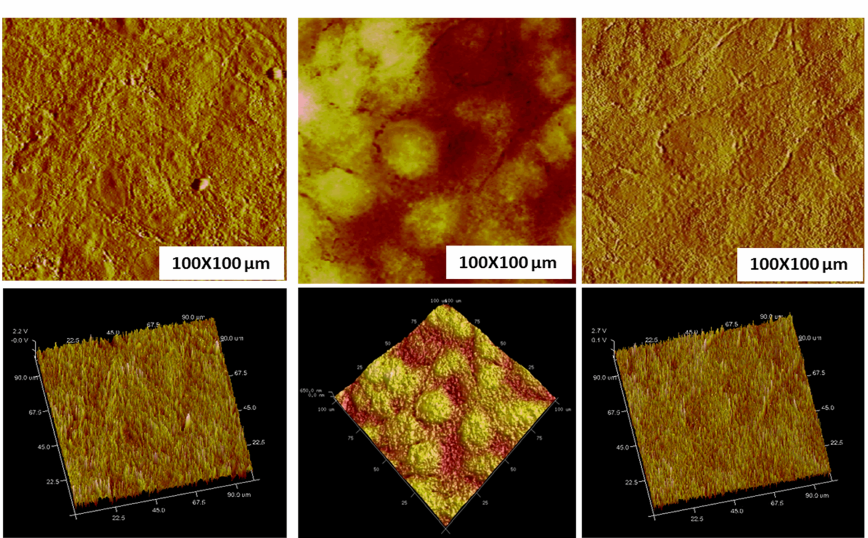

Figure 2

Further identification of hiPSC-RPE cells. (A) Identification of hiPSC-RPE cells (P1) using western blotting. (B) Representative flow cytometry histograms of hiPSC, hiPSC-RPE (P1), and hRPE cells. (C) 2D and 3D topography images of hiPSC, hiPSC-RPE (P1), and hRPE cells by AFM. 


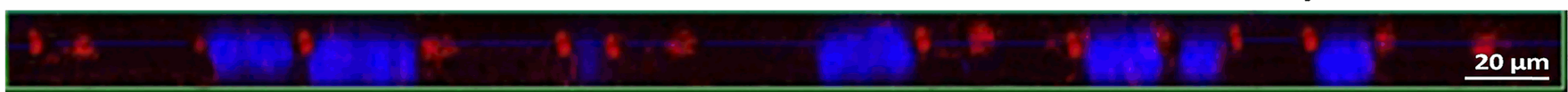

hiPSC-RPE

Basal side

Apical side

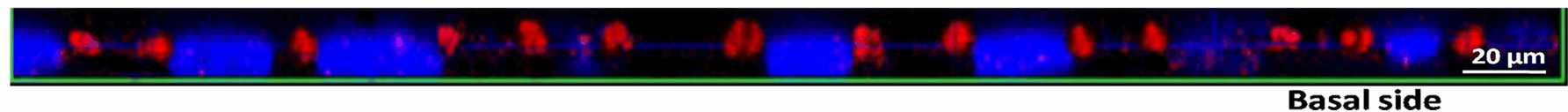

B

\section{hRPE}

\section{hiPSC-RPE}
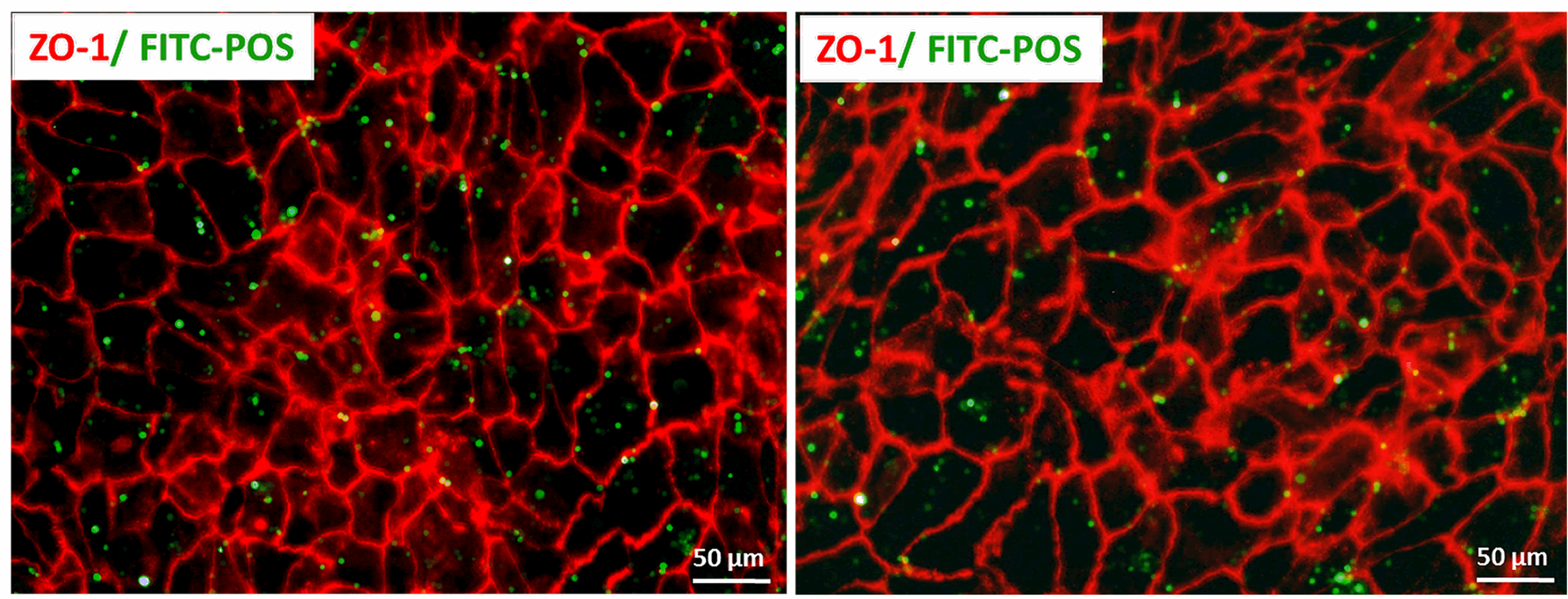

C
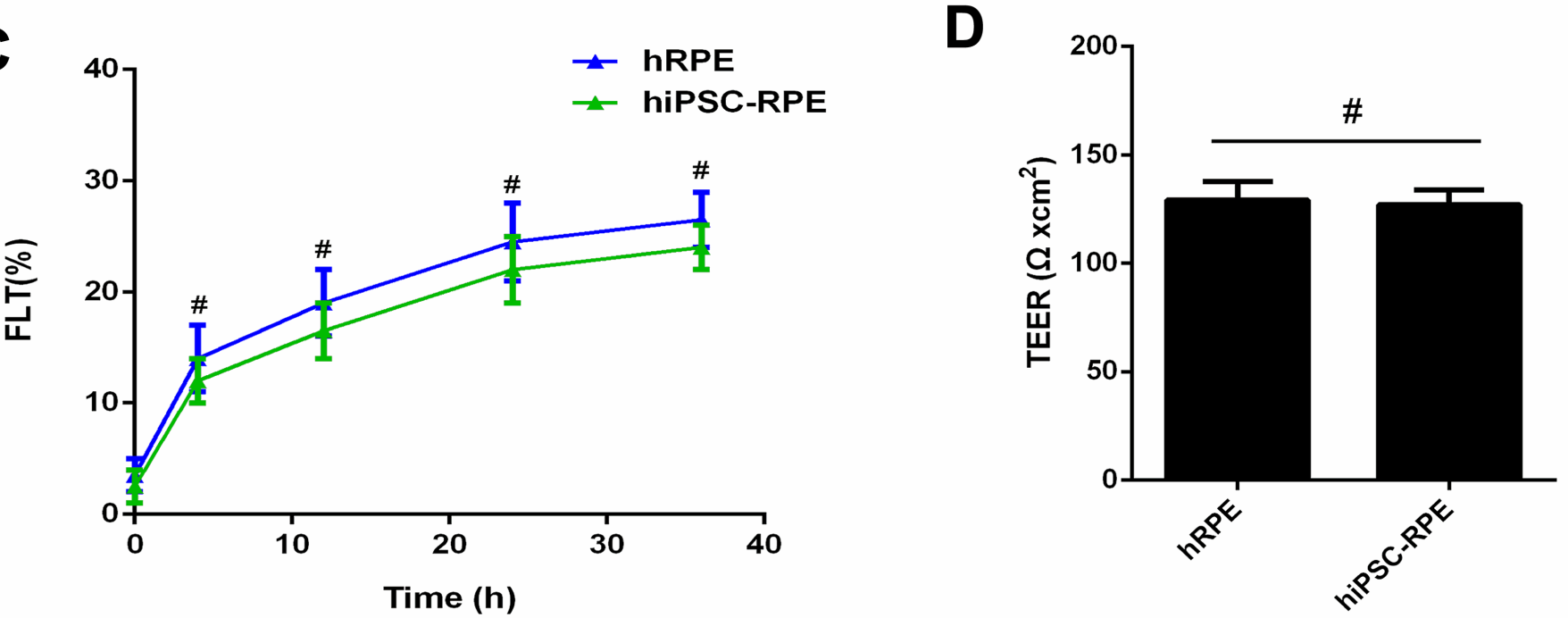

Figure 3

Identification of RPE-like function in hiPSC-RPE cells. (A) A Z-stack confocal micrograph showing typical polarized expression of ZO-1 demonstrated apical localization in hRPE and hiPSC-RPE cells. (B) The phagocytosis of FITC-POS and ZO-1 staining in hRPE and hiPSC-RPE cells. (C) The comparison of a dynamic barrier of hRPE and hiPSC-RPE cells through a fluorescein leakage test at 0, 4, 12, 24, and $36 \mathrm{~h}$. 
(D) TEER assay assesses the dynamic barrier function in hRPE and hiPSC-RPE cells. Differences with \#P>0.05 (hRPE vs hiPSC-RPE) were considered not significant. Bars represent mean $\pm S E M, n=3$.

\section{A}

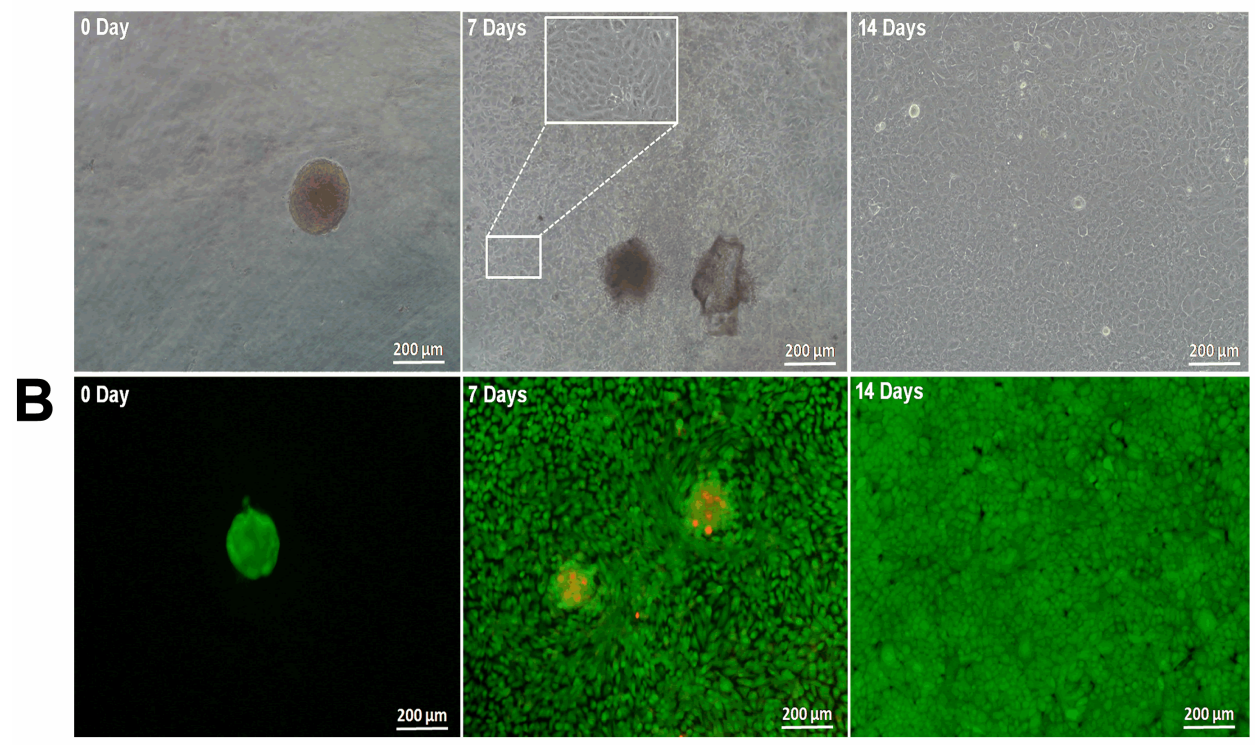

\section{Spheroid hiPSC-RPE}

D
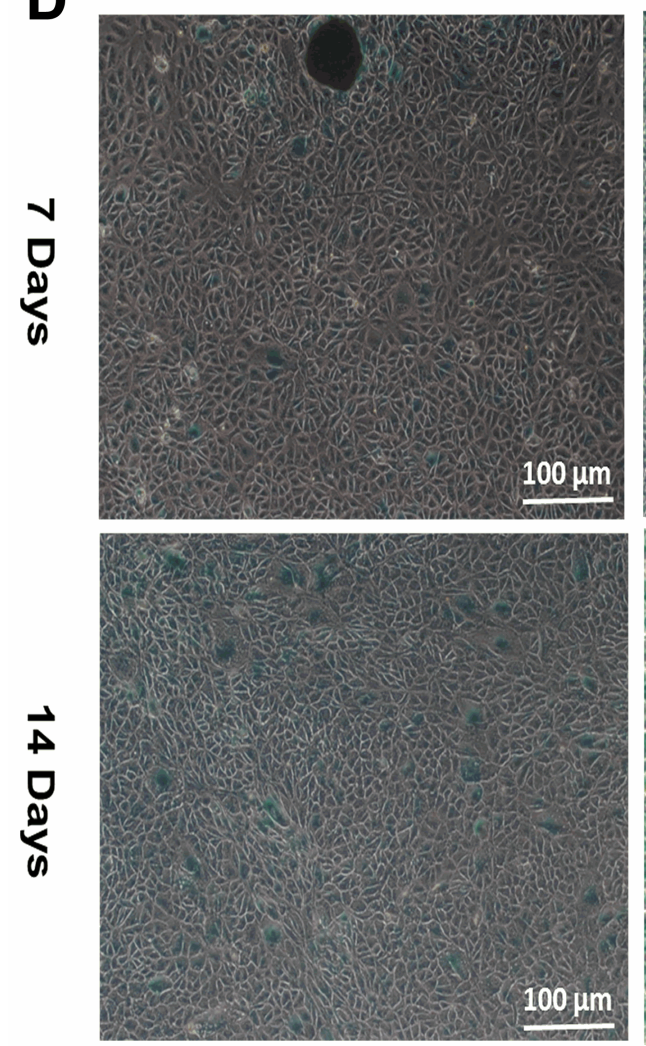

\section{Conventional hiPSC-RPE}
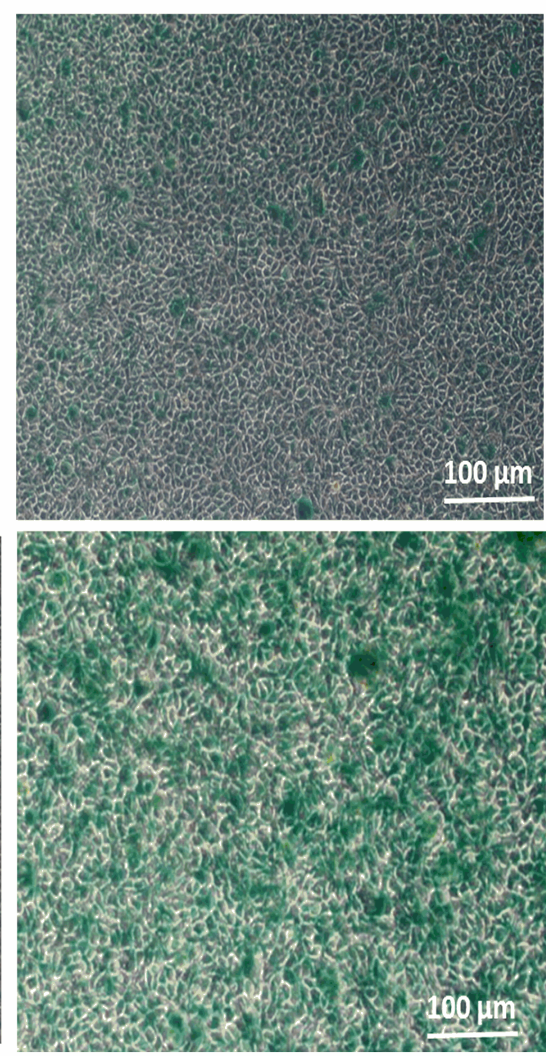

C Occludin/Mitf/DAPI
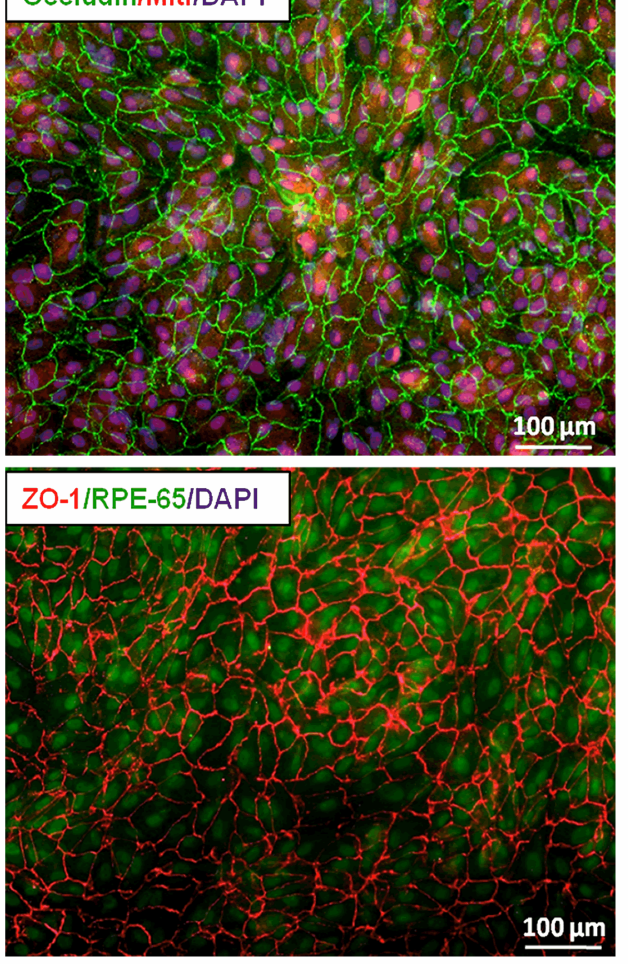

$\mathbf{E}$ Spheroid hiPSC-RPE
Conventional hiPSC-RPE

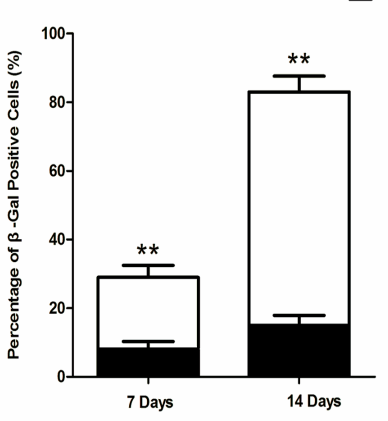

$\mathbf{F}$

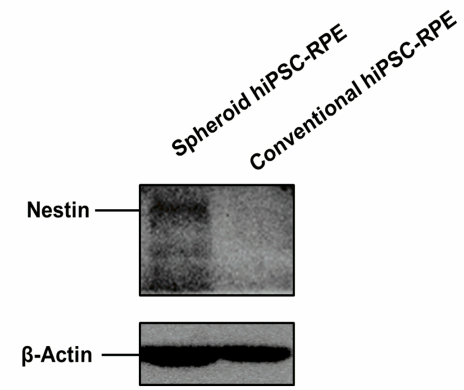

\section{Figure 4}

Seeding hiPSC-RPE cell spheroids on DCM. (A) Brightfield images of hiPSC-RPE cell spheroids on DCM on day 0,7 , and 14. (B) Calcein AM and EthD-IIl double staining of hiPSC-RPE cell spheroids on DCM on day 0,7 , and 14. (C) The double staining of Occludin and Mitf or ZO-1 and RPE-65 in hiPSC-RPE cell 
spheroids on DCM on day 14. (D) Detection of SA- $\beta$-Gal staining in spheroid or conventional culture hiPSC-RPE cells on days 7 and 14. (E) Quantification of SA- $\beta$-Gal staining with ImageJ software. (F) The expression of Nestin in spheroid or conventional culture hiPSC-RPE cells on day 14. A difference with ${ }^{*} \mathrm{P}<0.01$ (spheroid culture hiPSC-RPE vs conventional culture hiPSC-RPE on day 7 and 14) was considered statistically significant. Bars represent mean $\pm S E M, n=3$.
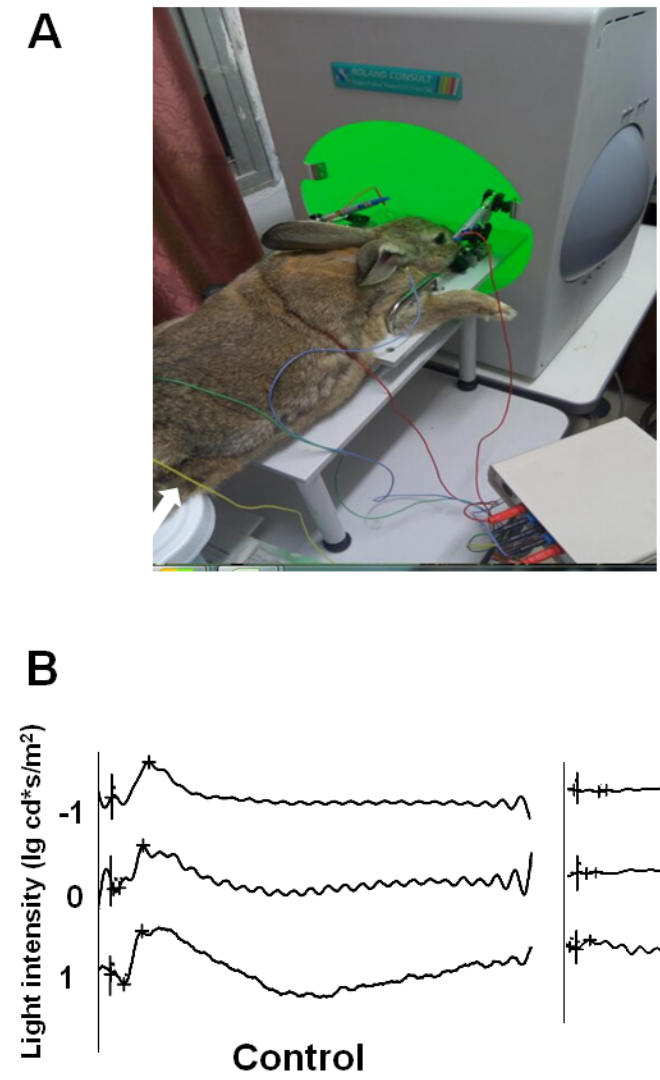

Figure 5

ERG recording of hiPSC-RPE cell spheroid transplantation in vivo. (A) The model of ERG system. (B) Changes in ERG responses in different groups in response to white flashes of increasing intensity after dark adaptation. (C) Mean b-wave amplitudes of different groups in response to white flashes of increasing intensity after dark adaptation. Differences with ${ }^{*} \mathrm{P}<0.05$ and ${ }^{*} \mathrm{P}<0.01$ were considered statistically significant. Difference with $\# P>0.05$ were considered insignificant. Bars represent mean \pm SEM, $n=3$. 
A
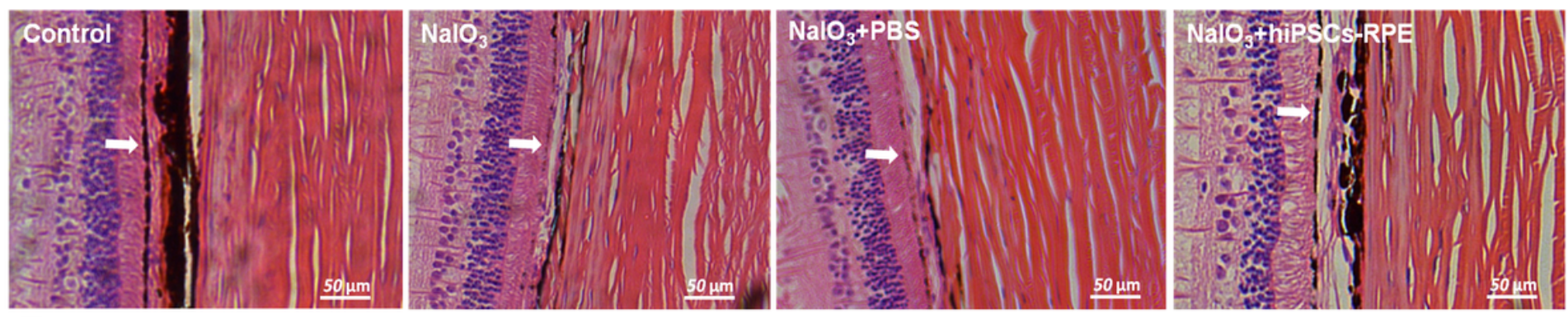

B

Control
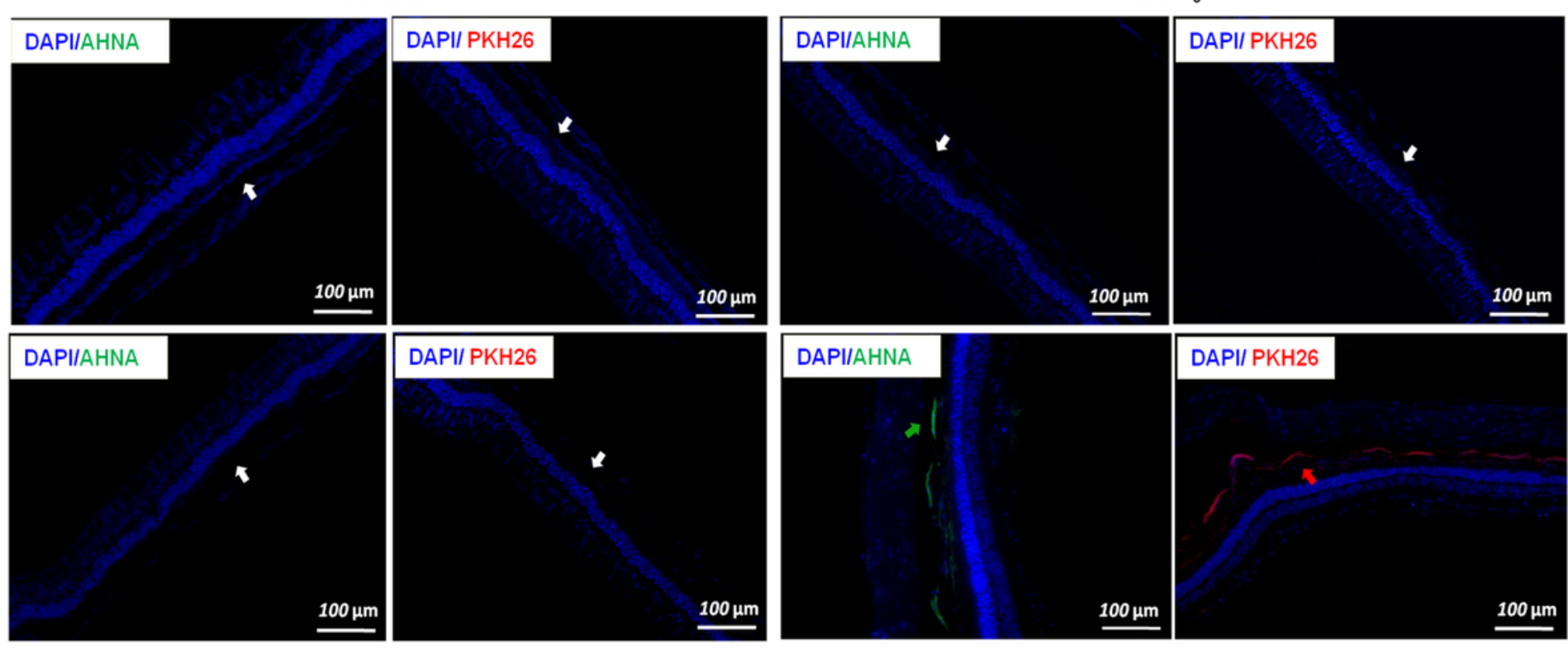

$\mathrm{NaIO}_{3}+\mathrm{PBS}$

$\mathrm{NaIO}_{3}+$ hiPSC-RPE

Figure 6

Preliminary test of hiPSC-RPE cell spheroids in vivo. (A) H\&E-staining of paraffin sections after one month of hiPSC-RPE cell spheroid injection in vivo (arrows represent RPE layer). (B) Immunohistochemistry of paraffin sections after one month of hiPSC-RPE cell spheroid injection in vivo (white arrow represents RPE layer in control, NaIO3, and NaIO3+PBS groups; green arrow represents AHNA positive of partial hiPSCRPE cell sheets in NalO3+hiPSC-RPE group; red arrow represents partial hiPSC-RPE cell sheets labeled PKH26 in NalO3+hiPSC-RPE group).

\section{Supplementary Files}

This is a list of supplementary files associated with this preprint. Click to download.

- FigureS4.tif

- FigureS1.tif

- Figures5.tif

- Figures2.tif 
- FigureS3.tif

Page $37 / 37$ 